\title{
๖The Increasing Role of Vegetation Transpiration in Soil Moisture Loss across China under Global Warming
}

\author{
MingXing Li, ${ }^{\mathrm{a}}$ Peili Wu, ${ }^{\mathrm{b}}$ Zhuguo Ma, ${ }^{\mathrm{a}, \mathrm{c}}$ Zhinua Pan, ${ }^{\mathrm{d}}$ Meixia Lv, ${ }^{\mathrm{a}}$ Qing YAng, ${ }^{\mathrm{a}}$ And Yawen Duan ${ }^{\mathrm{a}}$ \\ ${ }^{\text {a }}$ Key Laboratory of Regional Climate-Environment for Temperate East Asia, Institute of Atmospheric Physics, Chinese Academy of \\ Sciences, Beijing, China \\ ${ }^{\mathrm{b}}$ Met Office Hadley Centre, Exeter, United Kingdom \\ ${ }^{\mathrm{c}}$ University of Chinese Academy of Sciences, Beijing, China \\ ${ }^{\mathrm{d}}$ College of Resources and Environmental Science, China Agricultural University, Beijing, China
}

(Manuscript received 23 June 2021, in final form 1 December 2021)

\begin{abstract}
Changing pathways of soil moisture loss, either directly from soil (evaporation) or indirectly through vegetation (transpiration), are an indicator of ecosystem and land hydrological cycle responses to the changing climate. Based on the ratio of transpiration to evaporation, this paper investigates soil moisture loss pathway changes across China using five reanalysis-type datasets for the past and Coupled Model Intercomparison Project Phase 6 (CMIP6) climate projections for the future. The results show that across China, the ratio of vegetation transpiration to soil evaporation has generally increased across vegetated land areas, except in grasslands and croplands in north China. During 1981-2014, there was an increase by 51.4 percentage points (pps, $p<0.01$ ) on average according to the reanalyses and by 42.7 pps according to 13 CMIP6 models. The CMIP6 projections suggest that the holistic increasing trend will continue into the twenty-first century at a rate of $40.8 \mathrm{pps}$ for SSP585, 30.6 pps for SSP245, and $-1.0 \mathrm{pps}$ for SSP126 shared socioeconomic pathway scenarios for the period 2015-2100 relative to 1981-2014. Major contributions come from the increases in vegetation transpiration over the semiarid and subhumid grasslands, croplands, and forestlands under the influence of increasing temperatures and prolonged growing seasons (with twin peaks in May and October). The future increasing vegetation transpiration ratio in soil moisture loss implies the potential of regional greening across China under global warming and the risks of intensifying land surface dryness and altering the coupling between soil moisture and climate in regions with water-limited ecosystems.
\end{abstract}

KEYWORDS: Climate change; Ecosystem effects; Evapotranspiration; Soil moisture; Water budget/balance

\section{Introduction}

Soil moisture variability is a fundamental process linking Earth's energy, water, and carbon cycles and strongly regulates the regional climate (Seneviratne et al. 2010). Soil moisture can be transferred to the atmosphere from the soil by evaporation (a direct pathway) or through vegetation by transpiration (an indirect pathway). Changes in both the amount and the pathways of soil moisture loss reflect climate variability and can also trigger cascading actions in terrestrial environments (D'Odorico and Porporato 2004; Seneviratne et al. 2010). Under a changing climate, the anomaly of soil moisture loss is largely a signal of the effects of climate change and human activities on terrestrial environments (Diffenbaugh et al. 2015; Seneviratne et al. 2010). Therefore, understanding changes in soil moisture loss can help clarify the mechanisms of how the soil moisture balance varies with global warming and identify the potential effects of soil moisture loss on regional climate and terrestrial environments.

Soil moisture balance changes are significant to our climate and environment. On the one hand, soil moisture can

\footnotetext{
D Denotes content that is immediately available upon publication as open access.
}

Corresponding author: Mingxing Li, limx@tea.ac.cn "memorize" atmospheric anomalies such as drought events. On the other hand, soil moisture anomalies play an important role in regulating the spatiotemporal regimes of precipitation and dry-wet variability in critical zones (Koster et al. 2004; Li et al. 2020b). Building on the understanding of soil moisture's role in transferring water and energy between land and the atmosphere, Philip (1966) first used the concept of the soilplant-atmosphere continuum (SPAC) to highlight the effects of soil moisture on the whole simultaneous process. In this continuum, soil moisture plays a crucial role, regulating terrestrial water redistribution, solar radiation partitioning, and plant productivity. Observational evidence has demonstrated that soil moisture heterogeneity, which leads to convective initiation over drier soils, can create feedbacks that affect rainfall (Taylor et al. 2012); the state of heterogeneity is also the major control on runoff-precipitation responses (Robinson et al. 2008). For example, initial soil moisture conditions largely determine minor or severe flood damage in a storm event (Berthet et al. 2009). A typical exponential relation between soil moisture and surface albedo has also been corroborated in semiarid regions, and albedo decreases with an increase in soil moisture (Wang et al. 2005). The resulting variability in surface energy partitioning plays an important role in the monsoon climate system, which in turn affects the global energy and water cycles (Wu et al. 2012). Regarding soil moisture-climate interactions, Seneviratne et al. (2010) reviewed their coupling with precipitation, evapotranspiration and temperature and highlighted that soil moisture-climate 
feedbacks could increase but also dampen climate variability in various regions, and these feedbacks could be mediated by vegetation activities.

From the perspective of the biosphere, soil moisture can directly affect vegetation water and energy use efficiency in water-limited ecosystems. For example, soil moisture dominates dryness stress on more than $70 \%$ of vegetated land, especially in semiarid ecosystems (Liu et al. 2020). The terrestrial ecosystem capability of carbon sinks is also highly dependent on soil moisture conditions (Green et al. 2019). In addition, soil moisture directly affects surface solar radiation partitioning, namely, the Bowen ratio. With increasing soil moisture, the ratio decreases rapidly, resulting in an increase in the net surface radiation and thus promoting the primary productivity of terrestrial ecosystems (Jones and Brunsell 2009).

Given the coupled roles played by soil moisture and vegetation in land-atmosphere interactions and the large portion of the global land surface that is vegetated (Piao et al. 2020), the partitioning of soil moisture loss, namely, the ratio of transpiration to soil evaporation, can indicate the general ways in which soil moisture affects land-atmosphere interactions through biotic (transpiration) and abiotic (soil evaporation) processes. Extensive studies have found that approximately $60 \%$ of soil moisture loss occurs biotically despite the large spread among various estimation methods and ecosystems (Lian et al. 2018; Nelson et al. 2020; Zhang et al. 2016, 2012; Zhou et al. 2016). This large proportion of soil water loss by transpiration is regulated mainly by deeper soil moisture that can be taken up by plant roots; in contrast, soil evaporation is controlled by the surface and upper soil moisture contents and thus occurs more slowly and substantially contributes to the characteristics of regional soil moisture-climate feedbacks (Koster and Suarez 1996; Seneviratne et al. 2010). Since transpiration is the process by which soil moisture is lost through plant stomata, accompanied by the absorption of carbon dioxide, the ratio of transpiration to soil evaporation can demarcate soil water limitations on ecosystem water use efficiency, gross primary productivity, and other service functions (Bonan et al. 2011; Chang et al. 2018; Zhang et al. 2017). Furthermore, plant transpiration links the biotic and abiotic processes of soil moisture loss and further correlates the regional water and energy balances to carbon budgets between the land and the atmosphere via biogeochemical processes and modulates the influences of the soil moisture balance on environments and regional climate.

Because of its important role in the land-atmosphere system, changes in the partitioning and balance of soil moisture have attracted increasing attention with a changing climate. Currently, in situ measurements are still sparse on global and regional scales (Jung et al. 2019; Williams et al. 2004). However, on specific ecosystem scales, observational efforts have confirmed the dominant role of vegetation transpiration in soil moisture loss. Its ratio can be dominated only by soil evaporation in the case of sparse canopies (Perez-Priego et al. 2018; Williams et al. 2004). A data-driven estimate of evapotranspiration revealed that global annual evapotranspiration increased from 1982 to 1997, and then the increase ceased until 2008 due to increased soil moisture limitations (Jung et al. 2010). Model simulations generally agree with the above estimate, showing an expansion of drying areas due to the globally widespread increases in potential evapotranspiration (Berg and Sheffield 2019a,b; Cook et al. 2014; Lian et al. 2018). In China, using a process-based model driven with remotely sensed vegetation data and meteorological observations, a study revealed an increasing trend in the ratio of transpiration to total evapotranspiration from 1982 to 2015 (Niu et al. 2019). During the same period, increasing evapotranspiration was observed over 104 catchments in humid south China, with $90 \%$ attributed to climate warming and $9 \%$ to vegetation greening (D. Zhang et al. 2020). In terms of soil moisture content, modeling studies suggest increases in northwest and southeast China but significant decreases across dry-wet transition zones ( $\mathrm{Li}$ and Ma 2015).

In response to changes in the terrestrial water cycle and climate warming, large-scale vegetation greening during recent decades has been observed (Piao et al. 2020). An ensemble of remote sensing data has shown that over half of global vegetated lands have been experiencing an increasing leaf area index (LAI) in the growing season since the 1980s (Zhu et al. 2016). Across China, vegetation greening has been observed over the same period, mainly in forests and croplands (Chen et al. 2019). With increasing concentrations of carbon dioxide, its fertilization effect acts as an important driver of vegetation greening, and additional contributions are made from land use changes, such as increases in crops, grasslands, and forests. Moreover, global warming has eased climatic constraints on temperature-limited ecosystems. As a component of the land-atmosphere system, vegetation process changes reflect the variability of water and energy balances with intensifying global change.

These studies have shown credible evidence of changes in terrestrial water, energy, and ecological systems during recent decades and the pivotal role played by soil moisture in modulating these changes. Despite the considerable efforts that have been made to understand these changes, at the important node of land-atmosphere coupling, the response of the soil moisture balance to climate change remains somewhat unclear. This paper focuses on the changes in the pathways by which soil moisture is lost from the land surface, measured by the ratio of vegetation transpiration to soil evaporation. The goal is to quantify the impacts of climate change on soil moisture balance and terrestrial environments. Thus, five reanalysis-like datasets for present-day climate and 26 CMIP6 model simulations for three future emission scenarios were used, with details of these data and processing methods described in section 2. Their capability to depict soil moisture balance change was evaluated in terms of soil moisture, evapotranspiration, and transpiration using in situ observations and several benchmark datasets, as shown in section 3, and then the main results on the spatiotemporal features and changes from present-day climate to future scenarios follow. The possible mechanisms for the soil moisture balance's response to regional climate change, and implications for terrestrial environments in China, as well as the uncertainties in soil moisture balances and potential effects on the results, are 
TABLE 1. Information on the five reanalysis-related model datasets of soil moisture, evapotranspiration, soil evaporation, and transpiration data used in this study.

\begin{tabular}{|c|c|c|c|c|c|}
\hline Dataset & Institution & $\begin{array}{l}\text { Spatial resolution } \\
\text { (lat, lon) }\end{array}$ & $\begin{array}{c}\text { Soil layer } \\
\text { depths }(\mathrm{cm})\end{array}$ & $\begin{array}{l}\text { Land } \\
\text { model }\end{array}$ & $\begin{array}{l}\text { Temporal } \\
\text { coverage }\end{array}$ \\
\hline GLDAS & NASA $^{\mathrm{a}}$, United States & $0.25^{\circ} \times 0.25^{\circ}$ & $10,40,100,200$ & Noah-3.6 & 1948-2014 \\
\hline ERA5L & $\mathrm{ECMWF}^{\mathrm{b}}$ & $0.1^{\circ} \times 0.1^{\circ}$ & $7,28,100,289$ & HTESSEL $^{\mathrm{c}}$ & $1981-2020$ \\
\hline MERRA-2 & NASA, United States & $0.5^{\circ} \times 0.625^{\circ}$ & $\begin{array}{l}5,100, \text { to bedrock, nested } \\
\text { depths }\end{array}$ & Catchment & 1980-2020 \\
\hline 20CRv3 & NOAA $^{\mathrm{d}}$, CIRES $^{\mathrm{e}}, \mathrm{DOE}^{\mathrm{f}}$, United States & $1^{\circ} \times 1^{\circ}$ & $10,40,100,200$ & Noah & 1936-2015 \\
\hline GLEAM & Ghent University, Belgium & $0.25^{\circ} \times 0.25^{\circ}$ & $\begin{array}{l}\text { Surface }(5 \mathrm{~cm}) \text { and root } \\
\quad \text { zone }(5-100,5-250 \mathrm{~cm} \\
\text { for short, tall vegetation })\end{array}$ & & 1980-2020 \\
\hline
\end{tabular}

${ }^{\mathrm{a}}$ National Aeronautics and Space Administration.

${ }^{\mathrm{b}}$ European Centre for Medium-Range Weather Forecasts.

${ }^{\mathrm{c}}$ Carbon Hydrology-Tiled ECMWF Scheme for Surface Exchanges over Land.

${ }^{\mathrm{d}}$ National Oceanic and Atmospheric Administration.

${ }^{\mathrm{e}}$ Cooperative Institute for Research in Environmental Sciences at the University of Colorado.

${ }^{\mathrm{f}}$ Department of Energy.

discussed in section 4 . The paper is summarized with conclusions in section 5 .

\section{Data and methodology}

\section{a. Data}

\section{1) REANALYSIS DATASETS OF SOIL MOISTURE, EVAPOTRANSPIRATION, SOIL EVAPORATION, AND TRANSPIRATION}

To assess the changes in the pathways of soil moisture loss in the present-day climate, we used soil moisture, evapotranspiration, soil evaporation, and transpiration data from five reanalysis-related model datasets (referred to as reanalysis data for brevity).

1) The Global Land Data Assimilation System (GLDAS), version 2. The GLDAS dataset is generated by land models (here, only Noah-3.6 outputs were used) forced with bias-corrected meteorological data (Sheffield et al. 2006), providing a temporally consistent description of land processes for the period 1948-2014 (Rodell et al. 2004).

2) The rerun land data of the European Center for MediumRange Weather Forecasts climate reanalysis, fifth generation (ERA5L). This land dataset is reproduced with the ERA5's land model, H-TESSEL, forced by ERA5 atmospheric fields. High-resolution surface descriptions and thermodynamic orographic adjustments provide highresolution land variables (Dutra et al. 2020; Muñoz-Sabater et al. 2021).

3) The Modern-Era Retrospective Analysis for Research and Applications, version 2 (MERRA-2). Its land process dataset is generated with the coupled atmosphere-land system, in which precipitation is corrected by observations (Gelaro et al. 2017). Because only the energy fluxes $(F)$ for the three components of evapotranspiration were available, the equivalent water thickness $(W)$ in units of millimeters was estimated using $W=F / 2.501$, where the units are $10^{6} \mathrm{~W} \mathrm{~m}^{-2}$.

4) The Twentieth Century Reanalysis, version 3 (20CRv3). This dataset uses an upgraded data assimilation method relative to the previous version and assimilates a larger set of pressure observations (Slivinski et al. 2019).

5) The Global Land Evaporation Amsterdam Model, version 3.3a (GLEAM). GLEAM estimates evapotranspiration and root-zone soil moisture using vegetation optical depth, snow water equivalent, and reanalysis air temperature and radiation data, in addition to a multisource precipitation product. It also assimilates soil moisture data from passive and active microwave sensors (European Space Agency Climate Change Initiative, ESA CCI) and the Soil Moisture and Ocean Salinity (SMOS) satellite (Martens et al. 2017).

Details of the five datasets are listed in Table 1. In this work, monthly mean data for the period 1981-2014 were used to examine soil moisture loss due to present-day climate change. The five datasets were bilinearly interpolated onto the GLDAS spatial resolution $\left(0.25^{\circ} \times 0.25^{\circ}\right)$. However, the respective resolutions were used to evaluate their skill levels to describe the variability of soil moisture loss against observations across China. In addition, their surface downward solar radiation data were used to investigate the sensitivity of soil moisture loss changes to the surface energy balances.

\section{2) OBSERVATIONAL AND BENCHMARK DATA USED TO EVALUATE THE REANALYSES}

To justify the applicability of soil moisture-related variables in the five reanalysis datasets [section $2 \mathrm{a}(1)$ ] in China, we collected observational soil moisture data from 40 sites, four evapotranspiration benchmark products, and vegetation transpiration datasets from 10 sites and a model estimation with meteorological observations. Soil moisture observations were taken from the International Soil Moisture Network (ISMN, https://ismn.geo.tuwien.ac.at) (Dorigo et al. 2011). For the 

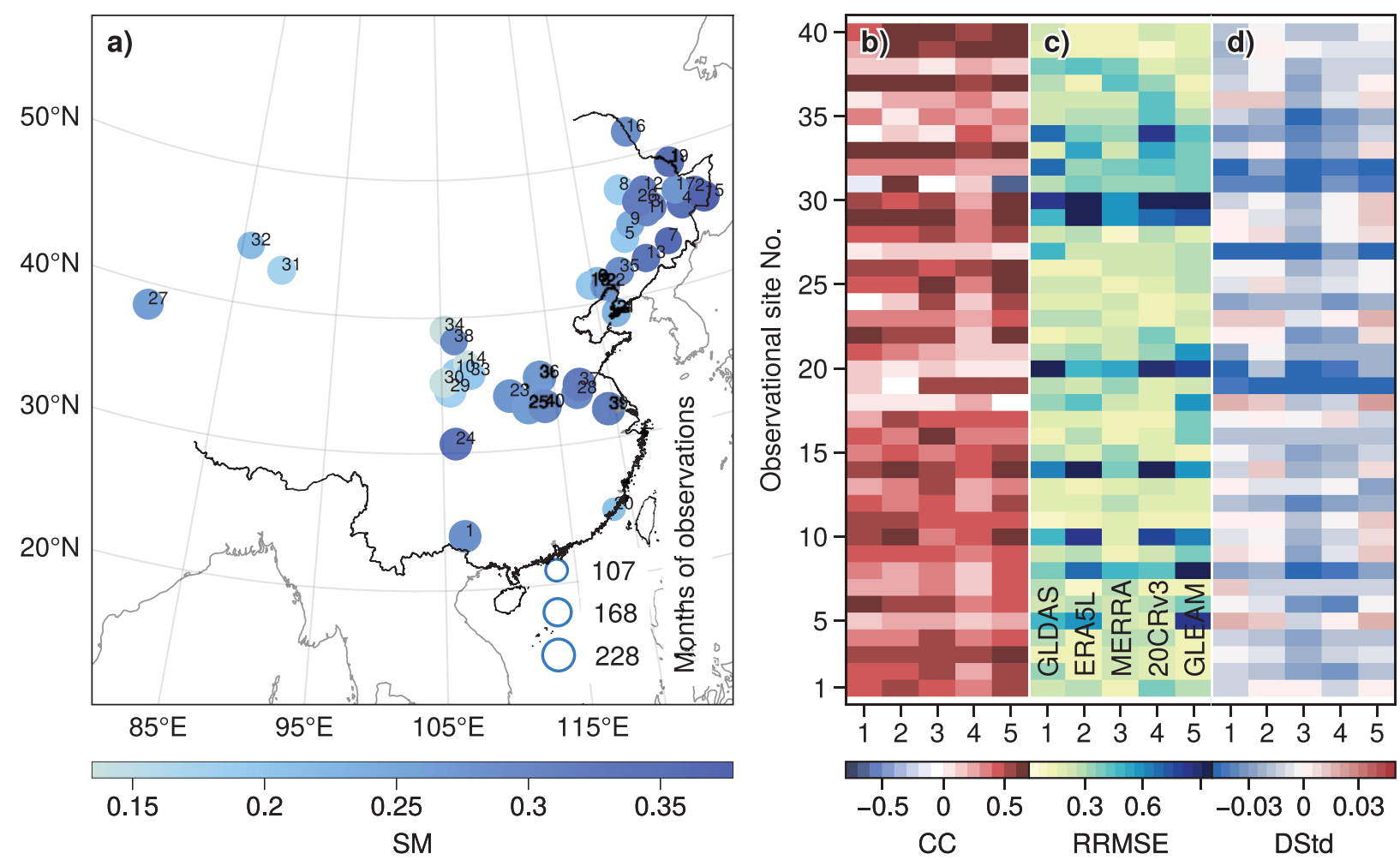

FIG. 1. (a) Geographical locations of observational sites for soil moisture, with mean soil moisture (SM) and month counts of observations [marker label indicates the site No. on the $y$ axis in (b)-(d)]. (b)-(d) The statistics between observations and reanalysis datasets (CC denotes the correlation coefficient, RRMSE is the ratio of RMSE to observational mean SM, and DStd indicates the difference in standard deviations between observations and model-based datasets).

period 1981-99, at 11 depths from 5 to $100 \mathrm{~cm}$, in situ observations were available at 10-day intervals, excluding rainy and frozen days. The geographical distribution of the 40 sites (Fig. 1a) covers the typical climate zones and vegetation ecosystems in China except for the Tibetan Plateau and deserts.

Given the lack of in situ observations at the regional scale in China, four benchmark products were used to jointly evaluate the five reanalysis evapotranspiration datasets. The four products included the following:

1) A synthesis product known as LandFlux-EVAL (Mueller et al. 2013), which was merged from 14 datasets from satellite and in situ observations and land model outputs (driven with observation-based or reanalysis forcings), covering the period 1989-2005. Its monthly dataset, with a spatial resolution of $1^{\circ} \times 1^{\circ}$ latitude and longitude, was used in this work.

2) The Climate Data Record (CDR) for the global terrestrial water budget during the period 1984-2010 (Zhang et al. 2018) combines multisource data on precipitation, evapotranspiration, runoff, and total water storage change to obtain the water budget closure by a constrained Kalman filter assimilation technique. The monthly CDR dataset at a spatial resolution of $0.5^{\circ} \times 0.5^{\circ}$ was used.

3) Remote sensing estimates were obtained with the Moderate Resolution Imaging Spectroradiometer (MOD16) by
Mu et al. (2011). MOD16 has a regular 1-km² resolution for global vegetated land areas, with 8-day, monthly, and annual data available during the period from 2000 onward.

4) Estimation by merging flux measurements from FLUXNET eddy covariance towers, remote sensing, and meteorological data with a machine learning method. The resulting dataset, known as FLUXCOM, is considered a benchmark to evaluate land process simulations (Jung et al. 2019). Its monthly dataset with $0.083^{\circ} \times 0.083^{\circ}$ resolution during 2001-14 was used in this research.

Vegetation transpiration measurements are publicly available for only 10 sites in China during 2003-10. These measurements were conducted by the Chinese Flux Observation and Research Network with the eddy covariance method (Yu et al. 2006). After data quality control and postprocessing, these measured values can be compared with the other records from the international FLUXNET sites (Yu et al. 2006). The details on the sites are listed in Table 2. Their monthly mean dataset during 2003-10 was used in this research.

Due to the scarcity of vegetation transpiration measurements available (Table 2), a model-based estimate was used to evaluate the spatial patterns and long-term trends of the five reanalyses on the regional scale. This dataset was generated with the Priestley-Taylor Jet Propulsion Laboratory model (PT-JPL) driven by observational meteorological data 
TABLE 2. Information on vegetation transpiration observations in China (http://chinaflux.org/enn/index.aspx; https://fluxnet.org; http://www.cnern.org.cn/index.jsp).

\begin{tabular}{|c|c|c|c|c|c|}
\hline No. & Site name & Abbr. & Location (lat, lon) & Vegetation type & Period \\
\hline 1 & Changbaishan & CBS & $42.40^{\circ} \mathrm{N}, 128.10^{\circ} \mathrm{E}$ & Forests & 2003-10 \\
\hline 2 & Changling & $\mathrm{ChL}$ & $44.59^{\circ} \mathrm{N}, 123.51^{\circ} \mathrm{E}$ & Grasslands & $2007-10$ \\
\hline 3 & Dangxiong & $\operatorname{DnX}$ & $30.50^{\circ} \mathrm{N}, 91.10^{\circ} \mathrm{E}$ & Grasslands & 2004-10 \\
\hline 4 & Dinghushan & DHS & $23.17^{\circ} \mathrm{N}, 112.53^{\circ} \mathrm{E}$ & Forests & 2003-10 \\
\hline 5 & Haibei (grasslands) & $\mathrm{HBG}$ & $37.67^{\circ} \mathrm{N}, 101.33^{\circ} \mathrm{E}$ & Grasslands & 2003-10 \\
\hline 6 & Haibai (wetlands) & HBW & $37.61^{\circ} \mathrm{N}, 101.33^{\circ} \mathrm{E}$ & Wetlands & 2004-09 \\
\hline 7 & Neimenggu & NMG & $43.33^{\circ} \mathrm{N}, 116.40^{\circ} \mathrm{E}$ & Grasslands & 2004-10 \\
\hline 8 & Qianyanzhou & QYZ & $26.74^{\circ} \mathrm{N}, 115.06^{\circ} \mathrm{E}$ & Croplands & 2003-10 \\
\hline 9 & Xishuangbanna & XSB & $21.61^{\circ} \mathrm{N}, 101.58^{\circ} \mathrm{E}$ & Forests & 2003-10 \\
\hline 10 & Yucheng & $\mathrm{YuC}$ & $36.83^{\circ} \mathrm{N}, 116.57^{\circ} \mathrm{E}$ & Croplands & 2003-10 \\
\hline
\end{tabular}

and satellite-based LAI, with a $0.05^{\circ} \times 0.05^{\circ}$ resolution during 1981-2015 (Niu et al. 2020). It is referred to as PT-JPL simulations hereafter. To evaluate not only the reanalysis transpiration but also its ratio to soil evaporation, the evapotranspiration additionally estimated with the Penman-Monteith-Leuning (PML) model (Zhang et al. 2016) was used because of the availability of the two corresponding components. The PML model was driven by atmospheric forcing based on reanalysis products, LAI data from the Advanced Very High Resolution Radiometer NDVI product, and emissivity and albedo data from the Global Land Surface Satellite products. The monthly mean evapotranspiration and its component data were available (http://doi.org/10. 4225/08/5719A5C48DB85) for $1981-2012$, with a $0.5^{\circ} \times 0.5^{\circ}$ spatial resolution. For more details on the model representation and simulation validation, refer to Zhang et al. (2016) and the references therein.

In addition, to detect varying vegetation responses to climate change, the Terra and Aqua combined MODIS land cover product (version 6, MCD12C1) was used to classify vegetation types in China (from https://pdaac.usgs.gov/products/ mcd12c1v006). According to the consistent types during 2001-10 (unless otherwise noted), their respective domains of land cover types were determined under the International Geosphere-Biosphere Programme classification scheme.

\section{3) CMIP6 SOIL MOISTURE, EVAPOTRANSPIRATION,} EVAPORATION, AND TRANSPIRATION OUTPUTS

To investigate the trend of soil moisture loss changes under future climate scenarios, we examined all the CMIP6 outputs of soil moisture, evapotranspiration, and transpiration for three shared socioeconomic pathway (SSP) scenarios (SSP126, SSP245, and SSP585). The models with three variables available are shown in Table 3, and detailed model information can be found online (https://wcrp-cmip.github.io/CMIP6_CVs). After some consistency checks, outputs from 13 models were finally selected. The evaluation is presented in section $3 \mathrm{a}(4)$.

\section{b. Methodology}

\section{1) STATISTICAL METRICS FOR EVALUATIONS OF REANALYSIS AND CMIP6 DATASETS}

In the processes of data evaluation and analysis, the following statistics are used: Pearson correlation coefficient $r$,

$$
r=\sum_{i=1}^{n}\left(x_{i}-m_{x}\right)\left(y_{i}-m_{y}\right) / \sqrt{\sum_{i=1}^{n}\left(x_{i}-m_{x}\right)^{2} \sum_{i=1}^{n}\left(y_{i}-m_{y}\right)^{2}},
$$

where $x_{i}$ and $y_{i}$ denote modeled and observed time series, respectively, with $n$ samples and $m_{x}$ and $m_{y}$ indicate their corresponding mean values. Then, the probability $p$ is estimated according to a $t$ distribution with $n-2$ degrees of freedom. If $p$ is less than a significance level (e.g., 0.05), $r$ is statistically significant.

The root-mean-square error (RMSE) is computed as follows:

$$
\mathrm{RMSE}=\sqrt{\frac{\sum_{i=1}^{n}\left(x_{m, i}-x_{o, i}\right)^{2}}{n}},
$$

where $x_{m, i}$ and $x_{o, i}$ are the modeled and observed variables, respectively, with sample size $n$.

The standard deviation (SD) was estimated using the following formula:

$$
\mathrm{SD}=\sqrt{\frac{\sum_{i=1}^{n}\left(x_{i}-m_{x}\right)^{2}}{n-1}} .
$$

In addition, the linear trend was estimated with least squares regression, and to validate the trend's significance, the two-sided $p$ value was calculated using the Wald test with $t$ distribution of the test statistic (Siniksaran 2005). For monthly variables, the Butterworth low-pass filter was applied prior to linear regression analyses (Winter et al. 1974). The pattern correlation coefficient was the Pearson productmoment coefficient of linear correlation for corresponding grid cells on two different maps of the same variable (IPCC 2001, appendix 12.3).

\section{2) SEASONAL TREND DECOMPOSITION OF REGIONALLY INTEGRATED SOIL MOISTURE DATA}

Given the limited in situ soil moisture observations, to test the periodicity and long-term trends of the five reanalysis soil moisture datasets in China, the integrated series were generated by averaging the soil moisture data over sites or 
TABLE 3. The currently available CMIP6 models with soil moisture loss-related outputs. Refer to the online tables on acronyms of institutions and models, and detailed model information (https://wcrp-cmip.github.io/CMIP6_CVs). An asterisk (*) indicates total soil moisture not available. A pound sign (\#) indicates soil moisture of soil layer not available at the time.

\begin{tabular}{|c|c|c|c|c|}
\hline No. & Model & Source ID & Land surface model & $\begin{array}{l}\text { Resolution } \\
(\text { lat } \times \text { lon })\end{array}$ \\
\hline 1 & BCC-CSM2-MR (Wu et al. 2019) & BCC, China & BCC-AVIM2 (Ji 1995) & $\sim 1.12^{\circ} \times 1.125^{\circ}$ \\
\hline 2 & CAMS-CSM1-0" (Rong et al. 2020) & CAMS, China & CoLM (Dai et al. 2003) & $\sim 1.12^{\circ} \times 1.125^{\circ}$ \\
\hline 3 & CanESM5 (Swart et al. 2019) & CCCma, Canada & $\begin{array}{l}\text { CLASS3.6/CTEM1.2 (Verseghy } \\
\text { et al. 1993) }\end{array}$ & $\sim 2.8^{\circ} \times 2.8^{\circ}$ \\
\hline 4 & CanESM5-CanOE ${ }^{\#}$ (Swart et al. 2019) & CCCma, Canada & $\begin{array}{l}\text { CLASS3.6/CTEM1.2 (Verseghy } \\
\text { et al. 1993) }\end{array}$ & $\sim 2.8^{\circ} \times 2.8^{\circ}$ \\
\hline 5 & CAS-ESM2-0 ${ }^{\#}$ (H. Zhang et al. 2020) & CAS, China & CoLM (Dai et al. 2003) & $\sim 1.4^{\circ} \times 1.4^{\circ}$ \\
\hline 6 & CESM2 (Danabasoglu et al. 2020) & NCAR, United States & CLM5 (Lawrence et al. 2019) & $\sim 0.94^{\circ} \times 1.25^{\circ}$ \\
\hline 7 & $\begin{array}{l}\text { CESM2-WACCM (Gettelman et al. } \\
\text { 2019) }\end{array}$ & NCAR, United States & CLM5 (Lawrence et al. 2019) & $\sim 0.94^{\circ} \times 1.25^{\circ}$ \\
\hline 8 & CMCC-CM2-SR5 (Cherchi et al. 2019) & CMCC, Italy & CLM4.5 (Lawrence et al. 2011) & $\sim 0.94^{\circ} \times 1.25^{\circ}$ \\
\hline 9 & CMCC-ESM2 (Cherchi et al. 2019) & CMCC, Italy & CLM4.5 (Lawrence et al. 2011) & $\sim 0.94^{\circ} \times 1.25^{\circ}$ \\
\hline 10 & CNRM-CM6-1 (Voldoire et al. 2019) & CNRM-CERFACS, France & SURFEX (Voldoire et al. 2013) & $\sim 1.4^{\circ} \times 1.4^{\circ}$ \\
\hline 11 & CNRM-ESM2-1 (Séférian et al. 2019) & CNRM-CERFACS, France & SURFEXv8.0 (Decharme et al. 2019) & $\sim 1.4^{\circ} \times 1.4^{\circ}$ \\
\hline 12 & EC-Earth3-Veg (Döscher et al. 2021) & $\begin{array}{l}\text { EC-Earth-Consortium, } \\
12 \text { European countries }\end{array}$ & $\begin{array}{l}\text { HTESSEL and LPJ-GUESS (Balsamo } \\
\text { et al. 2009; Smith et al. 2014) }\end{array}$ & $\sim 0.70^{\circ} \times 0.70^{\circ}$ \\
\hline 13 & FGOALS-g3 $^{\#}$ (L. J. Li et al. 2020) & CAS, China & CAS-LSM (Xie et al. 2018) & $\sim 2.00^{\circ} \times 2.00^{\circ}$ \\
\hline 14 & FIO-ESM-2-0*\# (Bao et al. 2020) & FIO, China & CLM4.0 (Lawrence et al. 2011) & $\sim 0.94^{\circ} \times 1.25^{\circ}$ \\
\hline 15 & GFDL-ESM4 $^{\#}$ (Dunne et al. 2020) & NOAA-GFDL, United States & LM4.1 (Dunne et al. 2020) & $\sim 1.0^{\circ} \times 1.25^{\circ}$ \\
\hline 16 & GISS-E2-1-G (Kelley et al. 2020) & NASA, United States & GISS LSM (Schmidt et al. 2006) & $\sim 2.00^{\circ} \times 2.50^{\circ}$ \\
\hline 17 & $\begin{array}{l}\text { HadGEM3-GC31-LL (Williams } \\
\text { et al. 2018) }\end{array}$ & MOHC, United Kingdom & JULES (Best et al. 2011) & $\sim 1.25^{\circ} \times 1.875^{\circ}$ \\
\hline 18 & IPSL-CM6A-LR (Boucher et al. 2020) & IPSL, France & ORCHIDEE (Krinner et al. 2005) & $\sim 1.27^{\circ} \times 2.50^{\circ}$ \\
\hline 19 & KACE-1-0-G* (J. Lee et al. 2020) & NIMS-KMA, South Korea & JULES (Best et al. 2011) & $\sim 1.25^{\circ} \times 1.875^{\circ}$ \\
\hline 20 & MIROC6 (Tatebe et al. 2019) & MIROC, Japan & MATSIRO6.0 (Takata et al. 2003) & $\sim 1.4^{\circ} \times 1.4^{\circ}$ \\
\hline 21 & MPI-ESM1-2-HR (Müller et al. 2018) & MPI-M, Germany & JSBACH3.20 (Stevens et al. 2013) & $\sim 0.94^{\circ} \times 0.94^{\circ}$ \\
\hline 22 & MRI-ESM2-0 (Yukimoto et al. 2019) & MRI, Japan & HAL (Yukimoto et al. 2012) & $\sim 1.12^{\circ} \times 1.125^{\circ}$ \\
\hline 23 & NorESM2-LM (Seland et al. 2020) & NCC, Norway & CLM5 (Lawrence et al. 2019) & $\sim 1.9^{\circ} \times 2.5^{\circ}$ \\
\hline 24 & NorESM2-MM (Seland et al. 2020) & NCC, Norway & CLM5 (Lawrence et al. 2019) & $\sim 0.9^{\circ} \times 1.25^{\circ}$ \\
\hline 25 & TaiESM1 (W. L. Lee et al. 2020) & AS-RCEC, China Taipei & CLM4 (Lawrence et al. 2011) & $\sim 0.9^{\circ} \times 1.25^{\circ}$ \\
\hline 26 & UKESM1-0-LL (Sellar et al. 2019) & MOHC, United Kingdom & JULES (Best et al. 2011) & $\sim 1.25^{\circ} \times 1.875^{\circ}$ \\
\hline
\end{tabular}

corresponding grid cells along the time axes for both observations and reanalysis. The resulting series were decomposed with the method of seasonal trend decomposition based on local regression (LOESS, STL) (Cleveland et al. 1990) in an additive model as follows:

$$
Y_{t}=T_{t}+S_{t}+R_{t}, t=1,2, \ldots, N,
$$

where the regionally integrated soil moisture $\left(Y_{t}\right)$ is decomposed into the long-term $\left(T_{t}\right)$, seasonal $\left(S_{t}\right)$, and remaining $\left(R_{t}\right)$ components at time step $t$. Using least squares linear regression, the linear trend can be isolated from the long-term component, and the remaining nonlinear signal manifests repeated but nonperiodic long-term variability. The seasonal term indicates variations over a fixed period (e.g., annual), and the residual component consists of subseasonal signals (e.g., daily) and noise except for the seasonal and long-term components. With the method of seasonal trend decomposition, the periodic signals in soil moisture can be disentangled and validated on daily, seasonal, and secular scales. The core method in STL decomposition is LOESS smoothing through a weighting function. Rigorous mathematical deductions can be found in the literature (Cleveland et al. 1990; Cleveland 1979).

\section{Results}

\section{a. Evaluation of reanalyses and validation of CMIP6 simulations}

\section{1) SOIL MOISTURE}

Regarding the five widely used reanalysis-like datasets (Table 1), several evaluations have been performed on soil moisture using upper-layer observations (Dorigo et al. 2021; Li et al. 2020a). Herein, we focused on root layer soil moisture and cross examination with evapotranspiration and transpiration. Figure 1 shows the locations of the 40 sites with available root layer observations as well as their sample numbers, mean soil moisture values, and statistics of comparisons with reanalysis datasets. Their correlation coefficients with the five reanalyses ranged from -0.63 to 0.85 , significant at the $\alpha=0.05$ level at $87.0 \%$ of sites; the ratio of the RMSE to the observational mean soil moisture (RRMSE, Fig. 1c) ranged from 

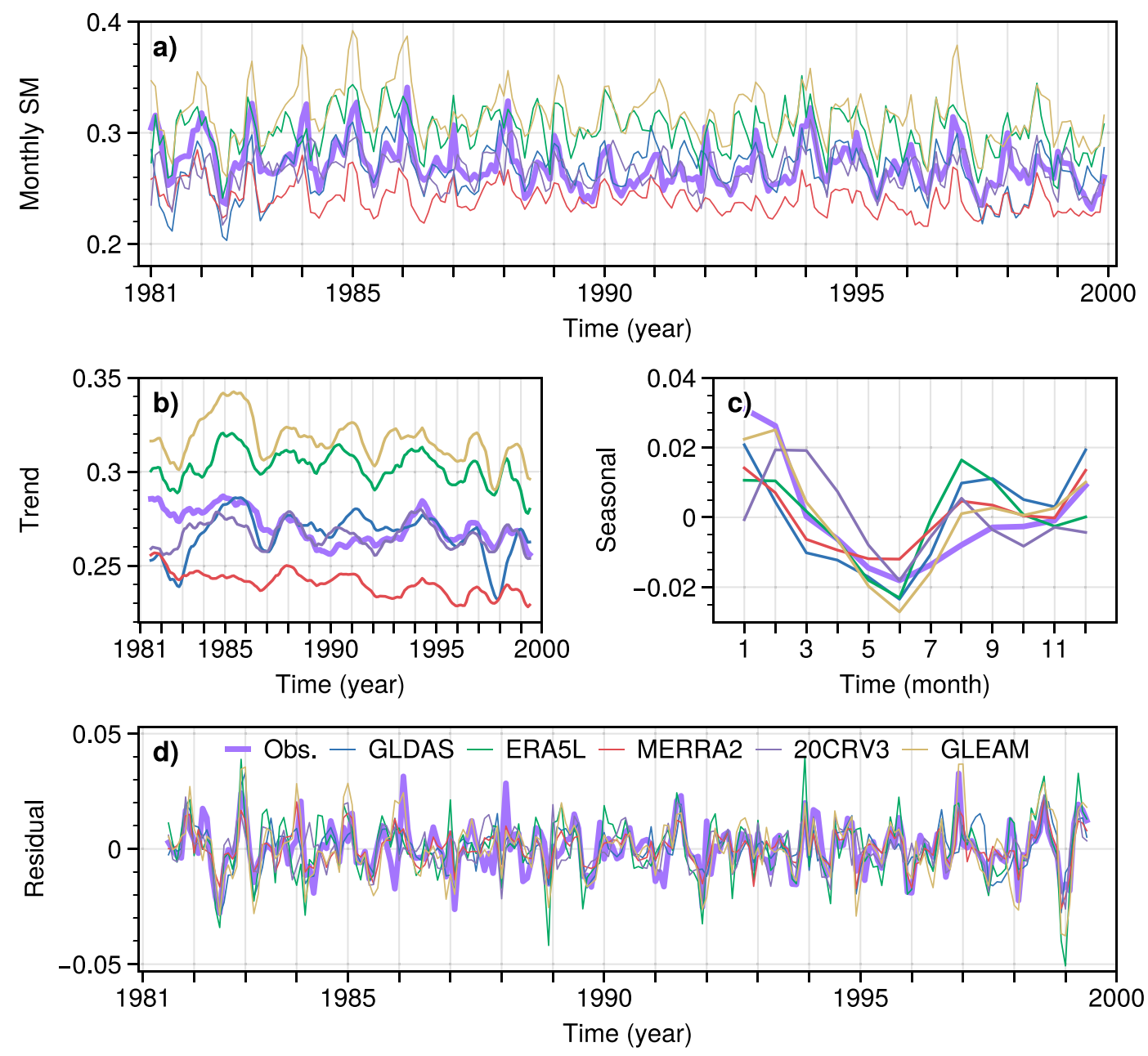

FIG. 2. Seasonal trend decomposition for integrated monthly soil moisture from all 40 sites and the corresponding five reanalysis datasets for the top 1-m soil layer, with statistics shown in Table 4.

$9.7 \%$ to $151 \%$; and the differences in standard deviations between observations and reanalyses (DStd, Fig. 1d) ranged from -0.06 to $0.02\left(\mathrm{~m}^{3} \mathrm{~m}^{-3}\right)$. These statistics show that the five reanalyses were in reasonable agreement with the observations in terms of the soil moisture in the top 1-m layer, and the consistency varied more across observational sites than across the reanalysis datasets. Their coarse grid resolutions constrained the reanalyses to capture the soil moisture heterogeneity observed at site points as well as the inadequacy of water and energy representations and land data in the reanalysis systems.

To reduce the local effects of sites, the concurrent observations were averaged across 40 sites, as were the reanalyses during 1981-99. Then, by means of seasonal trend decomposition, the skill levels of the reanalyses were evaluated on various temporal scales against the decomposed observations (Fig. 2). All five reanalyses, especially GLEAM and MERRA2, could regenerate the observed dynamics on a monthly scale in terms of the correlation coefficient $(p<0.01)$ (Fig. 2a, Table 4). Although seasonal cycles contribute to a large portion of the consistency (Fig. 2c, Table 4), the variations at low and high frequencies (trend and residual terms, Figs. 2b,d) were also in high agreement (with significant correlations, $p<0.01$, Table 3 ). According to the linear trends, while the reanalyses tended to underestimate the long-term trend, two reanalyses, GLEAM and MERRA2, reproduced the observed decreasing trend with remarkable accuracy (Table 4). However, the two reanalyses mostly over/underestimated the mean soil moisture of the top $1 \mathrm{~m}$ layer. The better performance of GLEAM largely benefits from the fine footprint of remote sensing retrievals (Martens et al. 2017); however, the coarse grid cells somewhat hampered the ability of the $20 \mathrm{CRv} 3$ to present the soil moisture dynamics observed at the point scale (Table 1).

\section{2) EVAPOTRANSPIRATION}

Evapotranspiration, a core component of soil moisture loss, was evaluated using four benchmark datasets [EVAL, CDR, 
TABLE 4. Statistics of seasonal trend decomposition analysis for the five reanalysis and observational soil moisture datasets (Fig. 2). Two asterisks $(* *)$ denote significances at the $p<0.01$ level; $\mathrm{v} / \mathrm{v}$ is volume ratio.

\begin{tabular}{llrrrrr}
\hline \hline \multicolumn{1}{c}{ Statistics } & & GLDAS & ERA5L & MERRA2 & 20CRv3 & GLEAM \\
\hline Correlation coefficients & Monthly SM & $0.52^{* *}$ & $0.56^{* *}$ & $0.72^{* *}$ & $0.52^{* *}$ & $0.77^{* *}$ \\
& Trend & $0.59^{* *}$ & $0.43^{* *}$ & $0.58^{* *}$ & $0.49^{* *}$ & $0.59^{* *}$ \\
& Seasonal & $0.70^{* *}$ & $0.59^{* *}$ & $0.79^{* *}$ & $0.49^{* *}$ & $0.94^{* *}$ \\
& Residual & $0.58^{* *}$ & $0.64^{* *}$ & $0.68^{* *}$ & $0.52^{* *}$ & $0.65^{* *}$ \\
Linear trends (v/v over 19 years) & -0.018 for obs. & -0.002 & $-0.009^{* *}$ & -0.017 & -0.003 & -0.018 \\
\hline
\end{tabular}

MODIS, and FLUXCOM; for details, see section 2a(2)]. Their significant correlations $(p<0.05)$ with the five reanalyses indicated that the reanalyses could regenerate the monthto-month variability in the benchmark data in the various periods [section $2 \mathrm{a}(2)]$. The long-term linear trends in the reanalyses showed the same increasing evapotranspiration as those in EVAL and CDR during their respective periods, despite considerable differences in the absolute magnitudes. With respect to MODIS and FLUXCOM, the spreads of linear trends among the reanalyses increased. Overall, ERA5L showed a closer trend to those of the benchmark data, followed by GLEAM. The regionally averaged annual cycles for their respective durations showed that, in China as a whole, the reanalysis means were larger than those of the modelbased datasets (EVAL and CDR) but smaller than those of the observation-based products (MODIS and FLUXCOM) (Fig. 3). Nevertheless, the reanalyses encouragingly captured the annual cycles in the benchmark datasets, with an identical peak in July. The significant pattern correlations (all larger than $0.78, p<0.01$ ) for the mean evapotranspiration across China further indicated the adequacy of the spatial structures of the reanalyses (figures not shown). Overall, the variability of reanalysis evapotranspiration was comparable with the established benchmark data for China.

\section{3) VEGETATION TRANSPIRATION AND ITS RATIO TO SOIL EVAPORATION}

For vegetation transpiration, another key component of soil moisture loss, the reanalyses were evaluated first using 10-site observations for the period 2003-10 (Table 2). At the monthly scale, the correlations were all significant $(p<0.05)$ as their annual cycles were retained. At the CBS, ChL, HBG, and QYZ sites, the much higher correlations across all the reanalyses largely resulted from the extensive spatial representativeness of in situ observations due to their homogenous surface conditions (Fig. 4a). Although the correlations declined considerably once their annual cycles were removed, GLEAM and ERA5L still had high levels of skill in presenting year-to-year variability (Fig. 4b). Likewise, in terms of errors (RMSE, Fig. 4c) and deviations (Fig. 4d), the spreads were larger across the sites than across the reanalysis datasets, and GLEAM was closest to the observations. From the perspective of linear trend, the five reanalyses all showed decreasing trends with the same sign as that of observations, and ERA5L displayed the closest decreasing trend to the observed trend.

Second, given the limited in situ observations, the PTJPL and PML model simulations were used to examine the spatial structure and long-term variability of reanalysis transpiration in China as a whole. The spatially averaged time series in China (Fig. 5a) showed that four of the five reanalyses captured the significant interannual variations in the PT-JPL and PML estimates $(r>0.55$ and 0.53 , $p<0.01)$ except for the MERRA-2 data, even after the strong signals of annual cycles were filtered out by annual averages (Table 5). The increasing trends in the regionally averaged reanalyses were also in agreement with those in the two model estimates, although the reanalyses were considerably weaker. Their arithmetic mean was close to the PML-simulated values but much less than obtained with the PT-JPL model. These statistics highlight the overall comparability of the temporal and spatial variability between the
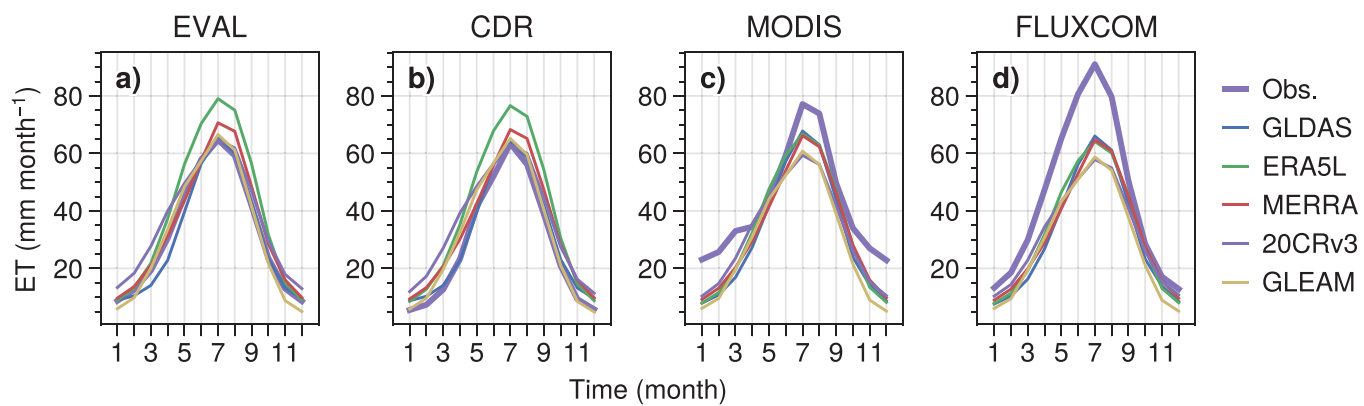

FIG. 3. Annual cycles of five reanalysis evapotranspiration vs four observation-based datasets. For each of the four panels, "Obs." represents the EVAL, CDR, MODIS, and FLUXCOM datasets, respectively. 
a)

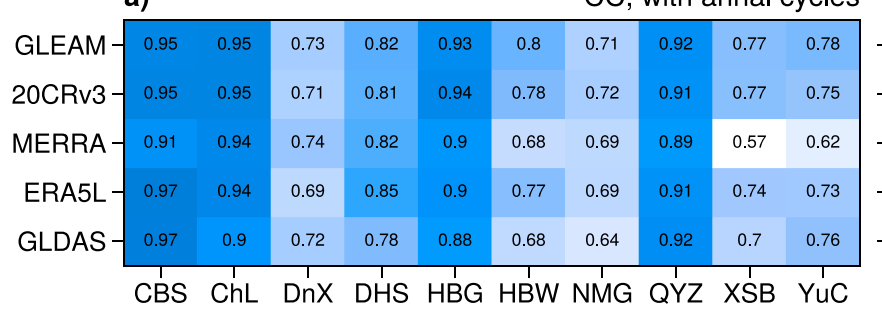

b) $\quad$ CC, without annual cycles, $>0.29$ sig. at $\alpha=0.05$

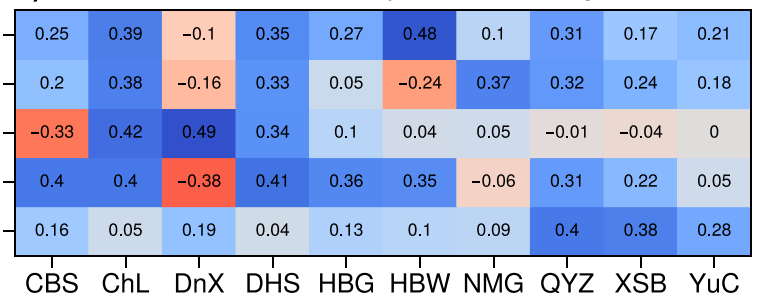

c)

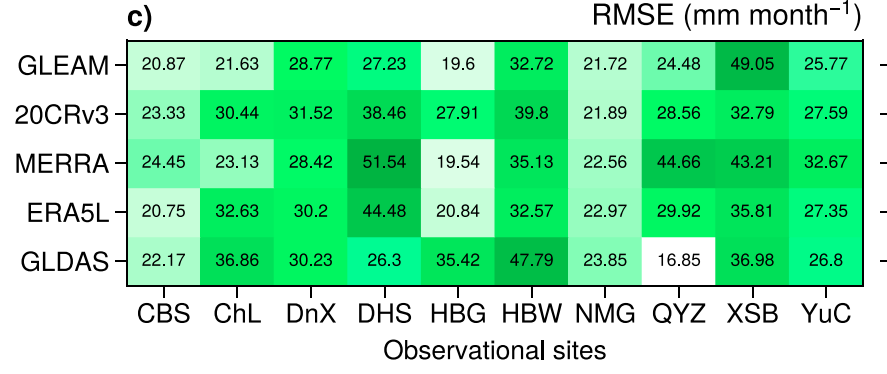

d)

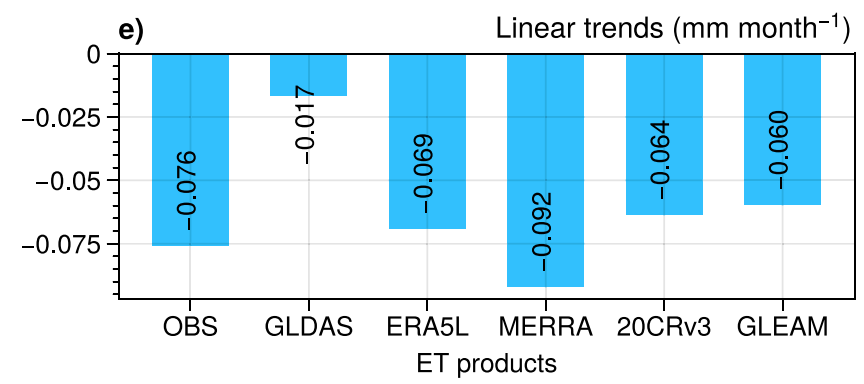

FIG. 4. Statistics for the comparisons among the five reanalysis vegetation transpiration datasets and in situ observations at 10 sites (Table 2) in China. Herein, STD denotes the standard deviation.

reanalysis transpiration datasets and the observation-driven estimates during the period 1981-2014.

The ratio of reanalysis transpiration to soil evaporation was further evaluated in comparison only with the PML simulations because components from both the observations and the PT-JPL data were unavailable (Fig. 5b). Among the reanalysis datasets, the spread of their annual mean ratios was broad (0.5-7.4 on average), which is attributed to the remarkably low ratio of MERRA-2 and the high ratio of GLEAM (Table 5). Nevertheless, their arithmetic mean ratio (2.6) substantially narrowed the spread with the PML simulations (1.6); the temporal dynamics were also in agreement to some degree, particularly the intensified fluctuations $(r=0.24, P=0.19)$. The mean linear trend ( 0.003 per year) also captured the increasing trend of the PML simulations (0.013 per year) despite the lower strength.

These evaluations of soil moisture, evapotranspiration, and vegetation transpiration, along with previous validations (Dorigo et al. 2021), confirmed that the five reanalysis datasets could reasonably represent soil moisture evolution across China at various temporal scales. Accordingly, the use of reanalysis data to detect soil moisture loss changes in China was justified at the time. The uncertainties in the data and their negative influence on the results are discussed in section 4 .

\section{4) CMIP6 VALIDATION AND SELECTION}

Given that the reanalysis data could reasonably regenerate the observed soil moisture processes, the CMIP6 simulations were validated and selected by comparing the results with the reanalyses. Analogous to the notion of the Bowen ratio, the ratio of vegetation transpiration to soil evaporation (VT/SV) is sensitive to the pathway changes in soil moisture loss from the land surface. Conditional on the plausibility of soil moisture, evapotranspiration, and soil evaporation simulations (figures not shown), the VT/SV ratio, as an indicator, was used to select the CMIP6 simulations that were suitable to quantify soil moisture loss changes across China. Figure 6 shows the pattern correlation coefficients (PCCs) and linear trend ratios for the VT/SV ratio between the 26 CMIP6 simulations and the reanalysis mean. Most CMIP6 simulations could reasonably regenerate the spatial pattern of the reanalysis VT/SV (PCC $>0.32$ at $\alpha=0.01$ ). However, it was more challenging for them to reproduce the long-term trends on the regional scale. Ruling out the simulations with opposite 

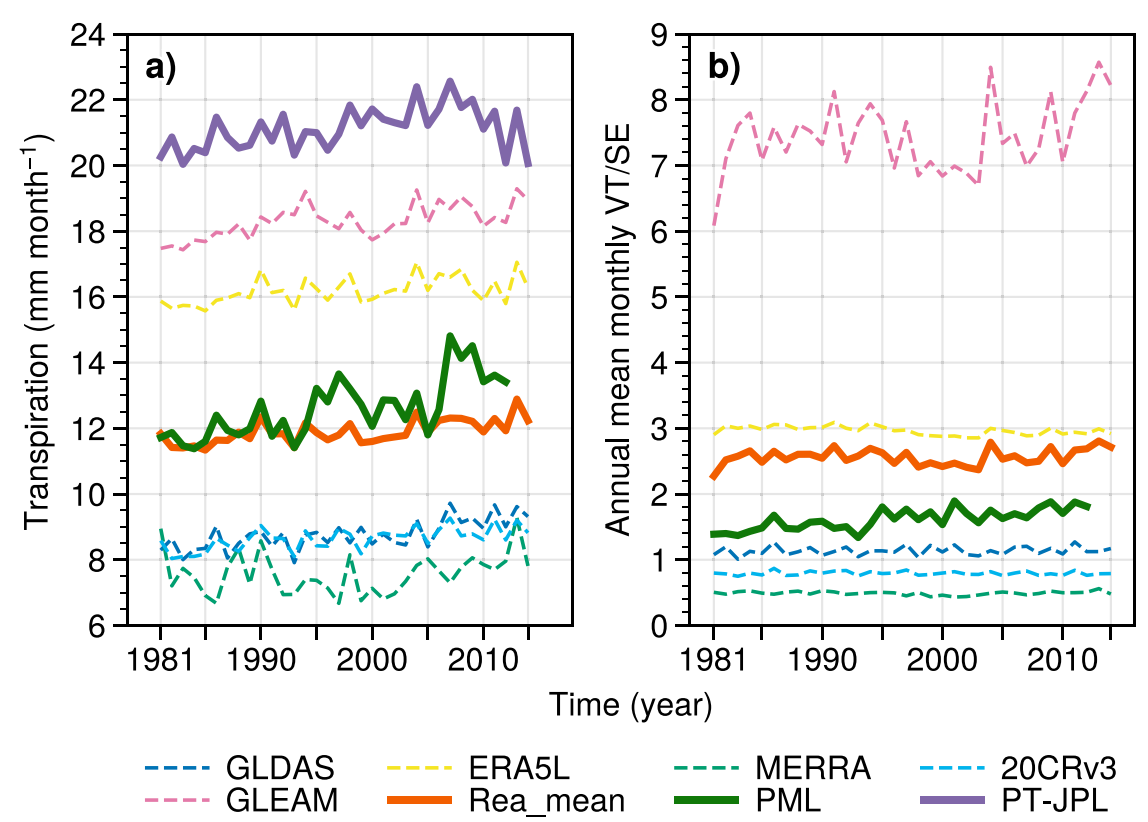

FIG. 5. Comparisons of (a) spatially averaged vegetation transpiration and (b) its ratio to soil evaporation in China for the five reanalysis datasets and the PML and PT-JPL simulations. Rea_mean denotes the arithmetic mean of the five reanalysis datasets.

linear trends over 1981-2014 and lower PCCs $(\mathrm{PCC}<0.32)$ for the means of that period, 13 of 26 model simulations were selected (with blue labels in Fig. 6). Note that we focused on the spatial patterns and long-term trends of the ratios in the CMIP6 outputs, and thus, we did not seek to evaluate the skill levels of soil moisture-related simulations in the CMIP6 models. Rather, the ratio was introduced to test the pathway changes of soil moisture loss from the land surface.

\section{b. Spatial structures of the soil moisture loss process in China over 1981-2014}

Based on the five reanalysis datasets over 1981-2014, the spatial structures of the core components related to soil moisture loss (Fig. 7) showed that soil moisture increased gradually from arid northwest China (less than $50 \mathrm{~mm}$ in the 0-1-m soil layer) to humid northeast and southeast China (approximately $400 \mathrm{~mm}$ ), generally following the pattern of precipitation; however, there were regional discrepancies due to the forcing from land processes such as the radiation balance, topography, vegetation, and soil properties (Ma et al. 2015). Evapotranspiration, which ranged from approximately 0-100 mm, showed a similar spatial gradient to that of soil moisture but decreased faster in northeastern China and the Tibetan Plateau under the constraint of radiation. Vegetation transpiration and soil evaporation broadly had equal shares of the evapotranspiration total (ranging from 0 to $50 \mathrm{~mm}$ ). Soil evaporation tended to be concentrated in humid regions while contributing to higher moisture loss across semiarid areas with lower vegetation cover (Fig. 7d).

TABLE 5. Statistics of the regional mean transpiration for the five reanalysis and observation-driven PT-JPL and PML estimation datasets (Fig. 5). $\mathrm{CC}_{\mathrm{PT}-\mathrm{JPL}}$ and $\mathrm{CC}_{\mathrm{PML}}$ denote the correlation coefficients between the reanalyses and PT-JPL and PML model simulations, respectively. The superscripts $* *$ and $*$ represent significance at the $p<0.01$ and 0.05 level, respectively; the subscripts a and $\mathrm{b}$ denote the statistics for Figs. 5a and 5b, respectively.

\begin{tabular}{|c|c|c|c|c|c|c|}
\hline & GLEAM & 20CR & MERRA & ERA5L & GLDAS & Rea_mean \\
\hline $\mathrm{CC}_{\mathrm{PT}-\mathrm{JPL}}$ & $0.55^{* *}$ & $0.66 * *$ & 0.01 & $0.68 * *$ & $0.58 * *$ & $0.57 * *$ \\
\hline $\mathrm{CC}_{\mathrm{PML}}$ & $0.53^{* *}$ & $0.64 * *$ & 0.04 & $0.54 * *$ & $0.82 * *$ & $0.66^{* *}$ \\
\hline $\operatorname{Trend}_{\mathrm{a}}\left(\mathrm{mm}\right.$ month $\left.^{-1} \mathrm{a}^{-1}\right)$ & $\begin{array}{c}\mathrm{CC}=0.64 \\
0.031 * * \\
\text { PT-JPL }=\end{array}$ & $\begin{array}{l}\text { en PT-JPI } \\
0.021 * * \\
*, \text { PML }=\end{array}$ & $\begin{array}{l}\mathrm{ML} \\
0.011\end{array}$ & $0.021 * *$ & $0.034 * *$ & $0.024 * *$ \\
\hline $\operatorname{Mean}_{\mathrm{b}}$ & $\begin{array}{l}7.37 \\
\text { mean }_{\text {PML }}\end{array}$ & 0.79 & 0.49 & 2.96 & 1.13 & 2.55 \\
\hline Trend $_{\mathrm{b}}$ (unitless) & $\begin{array}{l}0.018^{* *} \\
\text { Trend }_{\mathrm{PML}}\end{array}$ & $\begin{array}{l}-0.0002 \\
3 * *\end{array}$ & -0.0001 & -0.002 & 0.001 & $0.003 * *$ \\
\hline
\end{tabular}



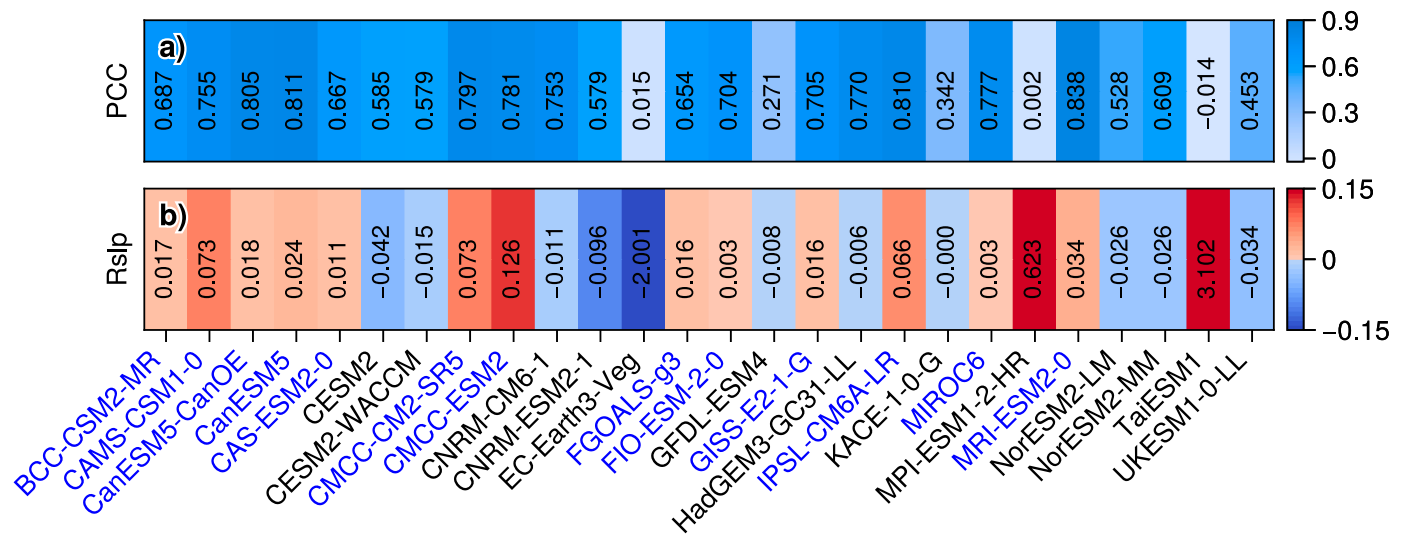

FIG. 6. Comparisons of the ratios of vegetation transpiration to soil evaporation (VT/SE) among 26 CMIP6 simulations and the reanalysis mean. (a) Pattern correlation coefficients (PCCs) of the mean VT/SE ratios over 1981-2014; (b) the relative slope (Rslp), the slope of the regional mean VT/SE ratio time series over 1981-2014 from CMIP6 divided by that from the reanalyses. The negative Rslp indicates that the slope in CMIP6 is opposite to that in the reanalyses. A value close to one indicates the trend is closer to that of the reanalyses. The blue color of the labels indicates the simulations selected for detecting soil moisture loss changes (section 3c).

Figure 8 shows the ratio of vegetation transpiration to soil evaporation (VT/SE), which depicts the partitioning of soil moisture loss between the two quantities. This ratio gradually increased from arid regions to humid regions, following the increase in vegetation cover. In arid regions, the ratio was less than 0.1 , so most soil moisture loss, if there was any, was due to the pathway of soil evaporation. With the increase in soil moisture and vegetation cover, the VT/SE increased from 0.5 to 1 and reached 1.5 in northeast and north China, which are mainly covered by croplands and forests. The ratio values were approximately $0.77,1.20,1.55,1.56$, and 1.91 in the areas dominated by grasslands, evergreen forests, deciduous forests, savanna, and croplands, respectively. The climatological drywet gradient (e.g., soil moisture) and vegetation cover types largely formed the pattern of the partitioning of soil moisture loss in China.

Figure 9 shows the seasonality of the VT/SE ratio. The ratios increased and expanded in spring with vegetation growth, especially in the croplands in north China. In summer, vegetation transpiration played a dominant role (VT/ $\mathrm{SE}>1.0$ ) in both proportion and area, especially in northeast China, with temperature constraints on the physiological processes of vegetation. From summer to autumn, cropland transpiration in north China played a major role in soil moisture loss because of the long period of agricultural production. In winter, larger VT/SE ratios emerged in subtropical southwest China. In these regions, the LAI of vegetation still retains $80 \%$ of its peak value during dry winter seasons (Song et al. 2017). With the decrease in topsoil moisture, the increased surface radiation partitioning contributed to the increase in the ratio. This variation was consistent with the observed higher transpiration and albedo in the dry season for the evergreen broadleaf forests in Cambodia, and this result was similar to the higher winter latent heat flux measured in an evergreen forest of north Thailand and the higher dry-season transpiration in northern
Australia (Nobuhiro et al. 2007; O’Grady et al. 1999; Tanaka et al. 2003).

\section{c. Pathway variability of soil moisture loss for the present-day climate}

During 1981-2014, there was an overall positive trend of soil moisture across China except in arid northwest China, semiarid northeast China, and humid southwest China (Fig. 10a). Evapotranspiration changes showed a similar spatial pattern but had stronger trends (Fig. 10b). Additionally, the pathway of soil moisture loss presented significant changes across China (Fig. 10c). The VT/SE ratio significantly increased in most areas covered by vegetation, from semiarid to humid areas. Larger increases appeared $[>10$ percentage points (pps) over 1981-2014] in northeastern croplands and forestlands and southern forestlands, with the maximum value (approximately $20 \mathrm{pps}$ ) in the southwestern forestlands. Slight increases appeared in parts of arid areas and the western Tibetan Plateau. Significant decreases $(<-10 \mathrm{pps})$ prevailed in north China, which is predominantly covered by grasslands and croplands.

Regarding the seasonality of VT/SE changes, the differences between the means over 2010-14 and 1981-85 (Fig. 11) showed that over north China, the persistent decrease from March to June totaled 36 pps with a trough value of $17 \mathrm{pps}$ in May, despite an increase of 11 pps in August (Fig. 11a). In contrast, across the regions with increasing trends, the VT/SE ratio increased year-round with a total increase of up to $91 \mathrm{pps}$, except for a decrease of 4.2 pps that emerged in May and June (Fig. 11b). In addition, the increases reached 15, 14, and 17 pps in February, August, and October, respectively. The decreases in north China around spring might have been a result of water stress affecting the growth of vegetation due to the aridification of soil moisture from winter to spring ( $\mathrm{Li}$ and Ma 2015; Li et al. 2020b). The increased ratio was largely associated with variations in soil moisture (Fig. 10a) and warming climate (Cao et al. 2016). The 

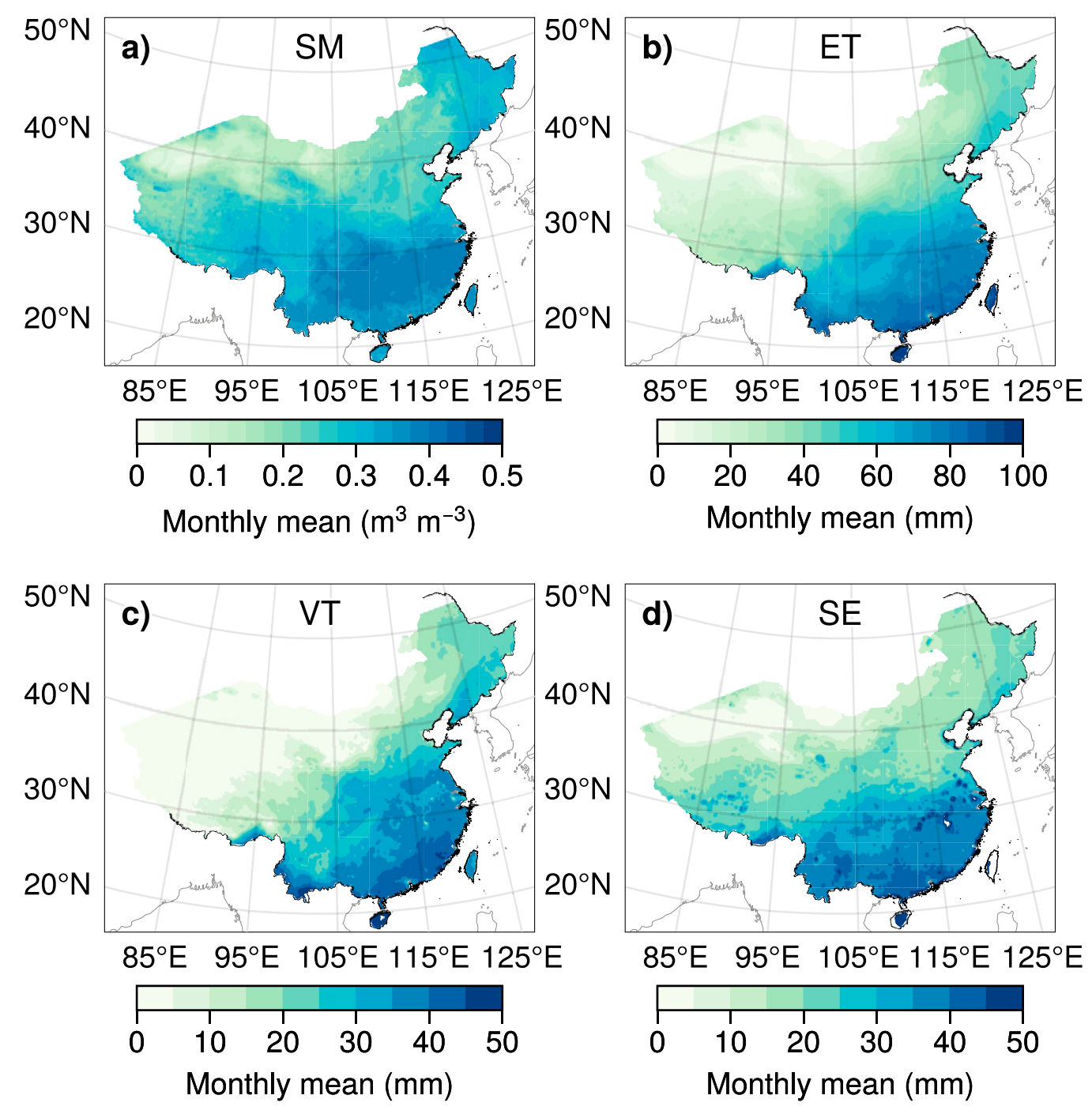

FIG. 7. Spatial distributions of (a) mean soil moisture (SM), (b) evapotranspiration (ET), (c) vegetation transpiration (VT), and (d) soil evaporation (SE) for the period 1981-2014 calculated from the reanalysis datasets.

potential mechanisms for the changes in the ratio are discussed in section 4 .

\section{d. Pathway changes in soil moisture loss under future climate scenarios}

Given that the pathway of soil moisture loss has been changing considerably across China with present-day climate change, the future tendencies of these changes are important because of their immediate relevance to our terrestrial environments. Figure 12 shows a comparison of the trends of the VT/SE ratios among the means of the 13 CMIP6 model historical simulations and five reanalysis datasets for the period 1981-2014. The selected CMIP6 models, based on their patterns of the mean VT/SE ratio and long-term dynamics (Fig. 6), considerably regenerated the spatial characteristics of the increasing VT/SE ratio in China; however, they failed to capture the decreasing trends in north China. The likely cause and potential implications of the results are further discussed in section 4. Given the discrepancy in trends in north China, the dynamics of the ratio, excluding north China with decreasing reanalysis trends, showed (Fig. 13) that the overall increase ratio in China was as high as 42.7 pps $(p<0.01)$ during 1981-2014 according to the 13 CMIP6 model simulation mean, and this value was comparable to that obtained by the reanalyses $(51.4 \mathrm{pps}, p<0.01)$. In the future from 2015 to 2100, the CMIP6 models project that the significant increasing trend is held consistently, reaching 30.6 pps under the SSP245 scenario (Mann-Kendall test, $\alpha=0.05$ ). The increase is as high as 40.8 pps under the SSP585 scenario. Under the SSP126 scenario, the dynamics show more periodic changes of 

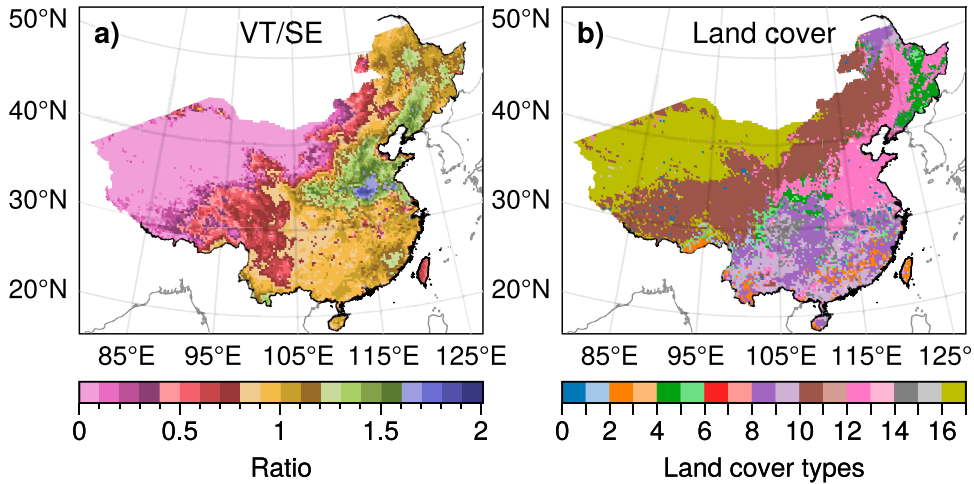

16 barren or sparsely vegetated

15 snow and ice

14 crop-natural-vegetation mosaic

13 urban and built-up

12 croplands

11 permanent wetlands

10 grasslands

9 savannas

8 woody savannas

7 open shrublands

6 closed shrubland

5 mixed forests

4 deciduous broadleaf forest

3 deciduous needleleaf forest

2 evergreen broadleaf forest

1 evergreen needleleaf forest 0 water

FIG. 8. Temporal mean spatial patterns of the VT/SE ratio distribution for the period 1981-2014 and land cover types in China in 2010.

decrease-increase-decrease with changepoints in 2031 and 2067, and the overall linear trend is -1.0 pps for the 85 -yr period.

In terms of the seasonality of the ratio changes (Fig. 14), the differences of the 2030s, 2060s, and 2090s means to the historical (1980-2014) mean show that, from the SSP126 to
SSP245 and SSP585 scenarios, the annual changes enhanced remarkably based on both means and variances. The means of the differences between the 2030s and the historical scenarios spanned from 2.1 to 3.7 pps, those between the 2060s and the historical scenarios spanned from 3.2 to $5.1 \mathrm{pps}$, and
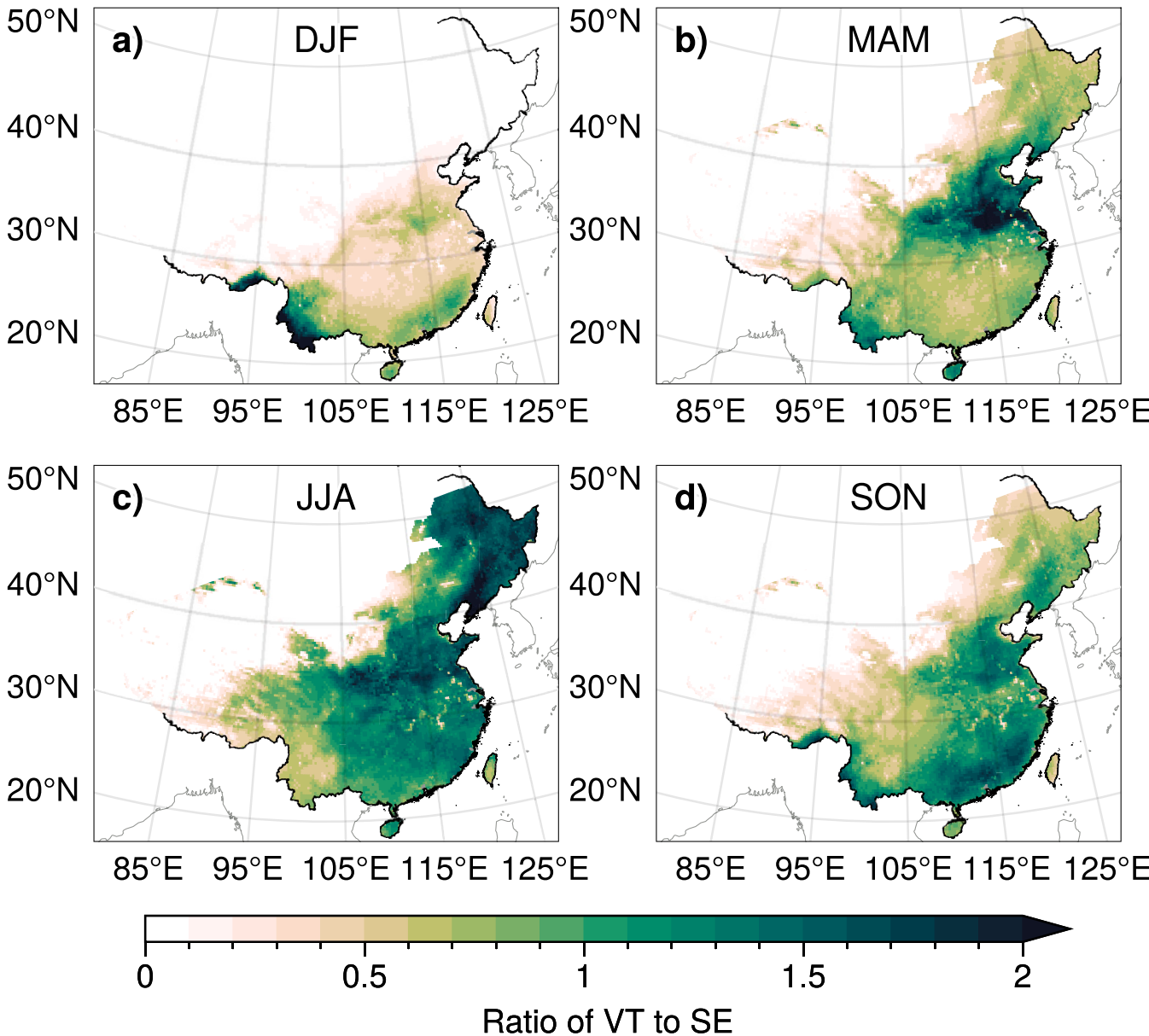

FIG. 9. Averaged seasonal patterns of the VT/SE ratio for the period 1981-2014. 

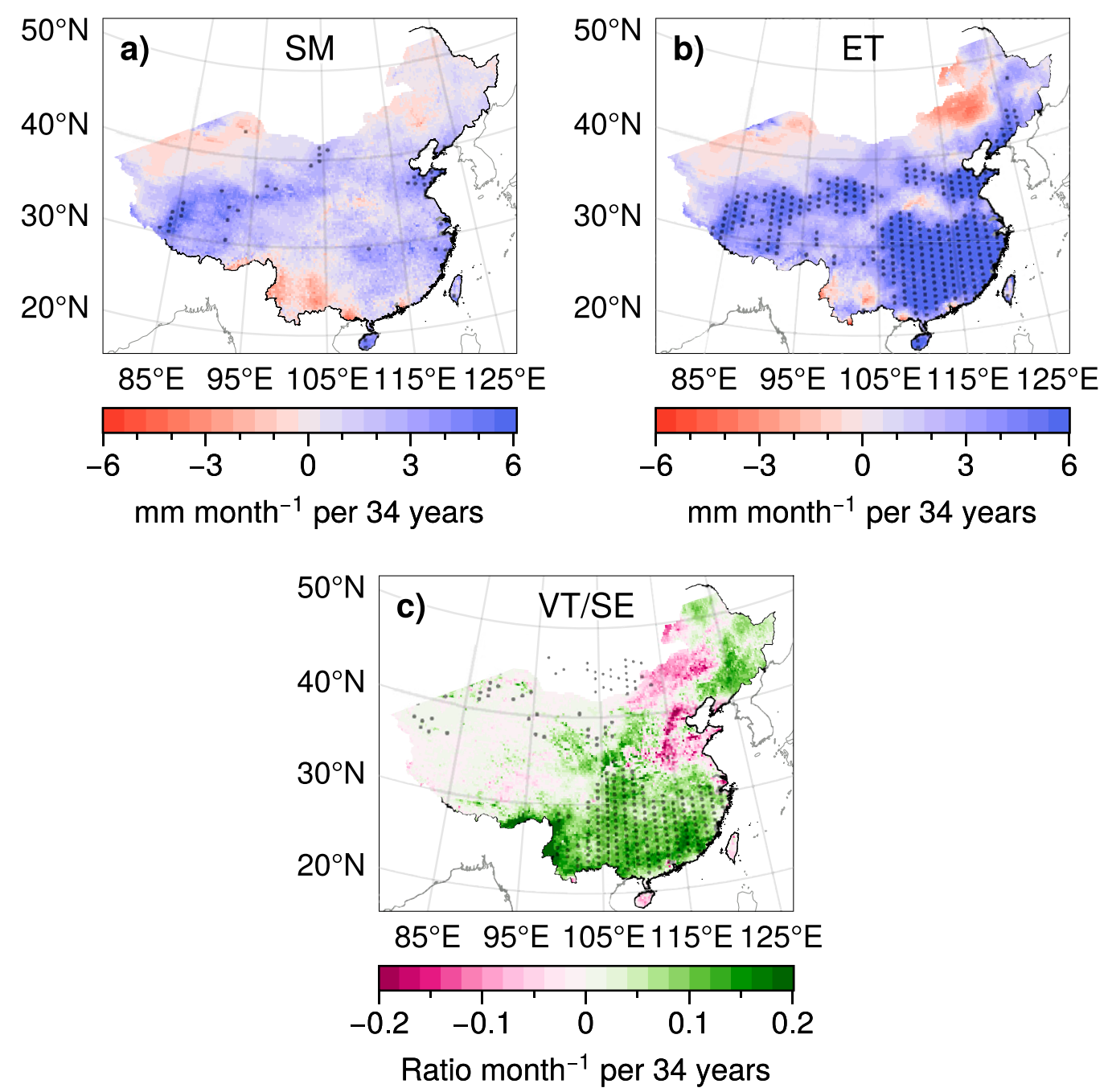

FIG. 10. Patterns of linear trends for soil moisture (SM), evapotranspiration (ET), and the ratio of VT to SE during 1981-2014. Dots indicate the significance of the slope by linear least squares regression at the $p<0.05$ level.

those between the 2090s and the historical scenarios spanned 2.5-4.9 pps. Additionally, the corresponding standard deviations were $1.6-1.9,2.7-4.2$, and $2.7-5.5 \mathrm{pps}$, respectively. In comparison with the historical scenario, the increases under the three scenarios were mainly produced in the spring and winter seasons, with peak increases in May (4.7-10.0 pps) and October (2.0-9.8 pps); additionally, peaks occurred in November for the 2060s and 2090s under SSP585 (10.4 and 11.2 pps, respectively). In contrast, the increases in summer substantially declined and even changed to negative values, especially in July, with decreases of $-1.7,-1.1$, and -7.9 pps in the 2090s under the three scenarios, respectively.

From the perspective of spatial construction, the VT/SE ratio changes (Fig. 15) were generally characterized by significant increases $(p<0.05)$ during the 2030s, 2060s, and 2090s compared with the historical baseline ratios (means over 1980-2014).
Under SSP245, an intermediate level of greenhouse gas emissions, the ratios increased across areas covered by vegetation throughout the 2030s, 2060s, and 2090s; additionally, larger increases $(>10 \mathrm{pps})$ appeared in the areas of grasslands and south China forestlands, and until the 2090s, the ratios tended to decline in southeast China forestlands. Under a low level of greenhouse gas emissions, SSP126, the increasing pattern was the same as that under SSP245 but with declining intensity in the 2030s and 2090s, especially the decreases $(<-5 \mathrm{pps})$ that appeared in southeast China. Under a high level of greenhouse gas emissions, SSP585, increases in the ratios were similarly held throughout the twenty-first century, with a maximum ( $>20 \mathrm{pps})$ in the 2060 s and decreases (from -5 to -20 pps) in east China in the 2090s. Under the three scenarios, grasslands, croplands, and evergreen forestlands contributed to the main increases in soil moisture loss by the vegetation pathway in China. 


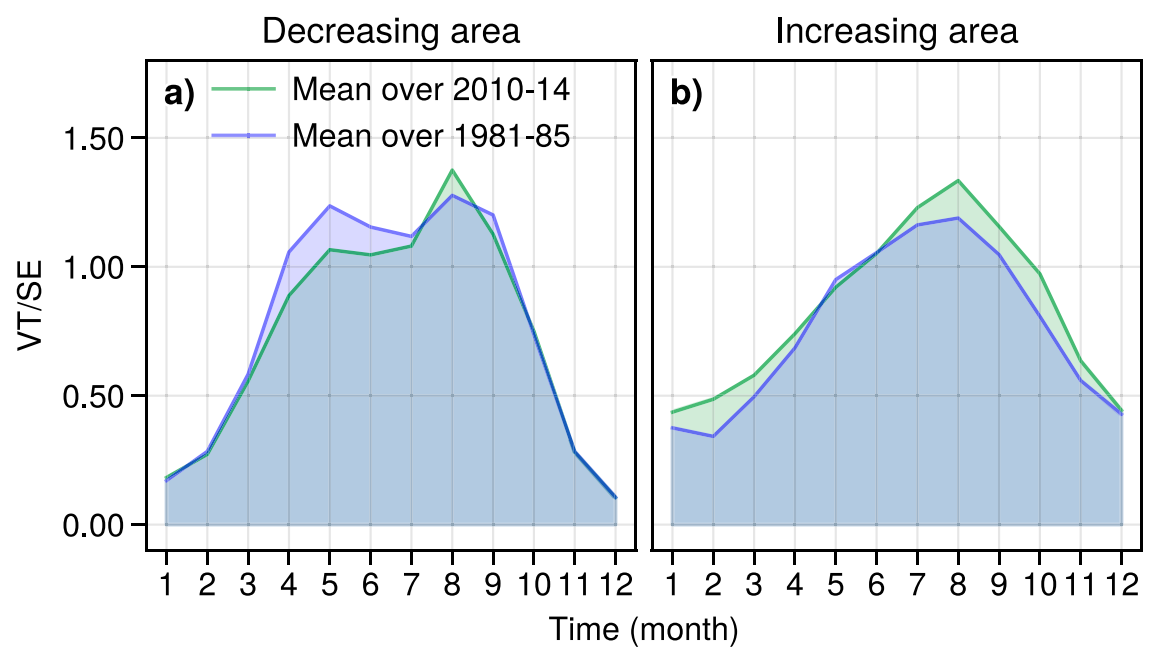

FIG. 11. Annual cycle comparisons of the mean VT/SE ratio between 1981-85 and 2010-14 in the areas with decreasing and increasing trends, respectively (shown in Fig. 10c).

\section{Discussion}

\section{a. Possible mechanisms of pathway changes of soil moisture loss}

In the present-day climate, the increasing VT/SE ratios of soil moisture loss are consistent with credible greening trends based on the long-term remote sensing LAI data of terrestrial ecosystems (Piao et al. 2020). A prominent greening pattern was observed in China during 2000-17, mainly from forests (42\%) and croplands (32\%) (Chen et al. 2019), and these results largely agreed with the trends from the CMIP6 models, especially regarding the greening of croplands in north China (Fig. 12b). In addition, an increasing seasonal LAI amplitude was observed in the remote sensing data (Cortés et al. 2021), which was analogous to the intensified annual cycle of the VT/ SE ratio (Fig. 11b) and future projections (Fig. 14). Piao et al. (2020) reviewed the drivers of greening trends of terrestrial ecosystems: human activities (afforestation and agricultural intensification) and global change (warming and carbon dioxide fertilization) are two dominant category drivers in China. Given that CMIP6 models do not explicitly represent the processes of

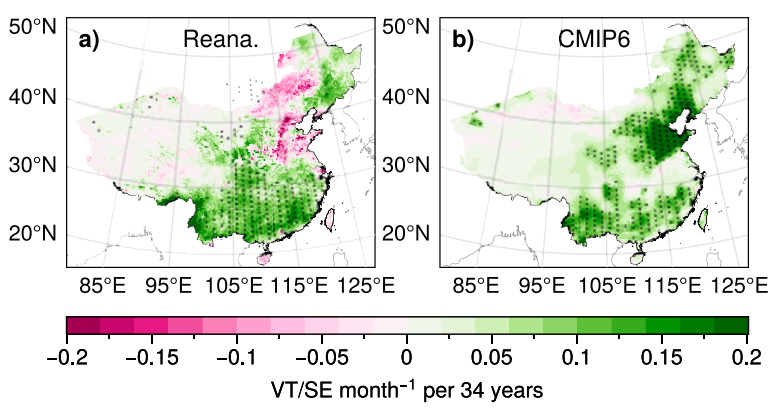

FIG. 12. Ensemble mean linear trends of the VT/SE ratio for the period 1981-2014 from (a) the five reanalysis datasets (Reana.) and (b) the 13 CMIP6 models. human activities, it can be expected that the increase in the VT/ SE ratio based on CMIP6 modeling is smaller than that in the reanalyses (which partly incorporate remote sensing data, e.g., GLEAM, Fig. 13a). Such a vegetation greening trend indicates increases in leaf size, leaf number, and plant density due to eased temperature constraints and carbon dioxide fertilization with a warming climate and intensified emissions (Lucht et al. 2002; Piao et al. 2020), thereby enhancing vegetation water competitiveness and use efficiency (Keenan et al. 2013). The increases in growing season length and water use efficiency dominantly underlie the increase in the ratio of vegetation transpiration in soil moisture loss relative to soil evaporation. In semiarid and subhumid regions, the enhancement of evaporation resistance due to drying in the upper soil layer ( $\mathrm{Li}$ and Ma 2015; Meng et al. 2021) contributes to an increase in the VT/SE ratio.

The projected VT/SE ratio increases in the future climate projections (SSP126, SSP245, and SSP585 scenarios), can largely be attributed to the same mechanisms as those in the present-day climate. The main reason is that the representations of biogeochemical processes in the Earth system models used for the CMIP6 projections have been incorporated in those used for the reanalysis simulations (Table 3 and references therein). Moreover, the 13-model mean LAI projection differences between the 2090s and 2020s under SSP585 showed significant increases in response to the warming climate in China (0.52 on average, figure not shown). Accordingly, with the warming climate and eased ambient conditions in part of growing season, enhanced vegetation water competitiveness and use efficiency are expected to contribute to the projected increases in the VT/SE ratio in the future climate scenarios.

Furthermore, due to the heterogeneity of climates and vegetation properties, the interactions between vegetation and climatic factors varied widely. From the perspectives of water (e.g., soil moisture) and energy (e.g., surface downward solar radiation) (Fig. 16), in grasslands, which are drier areas, the soil moisture loss pathway is primarily regulated by the water 


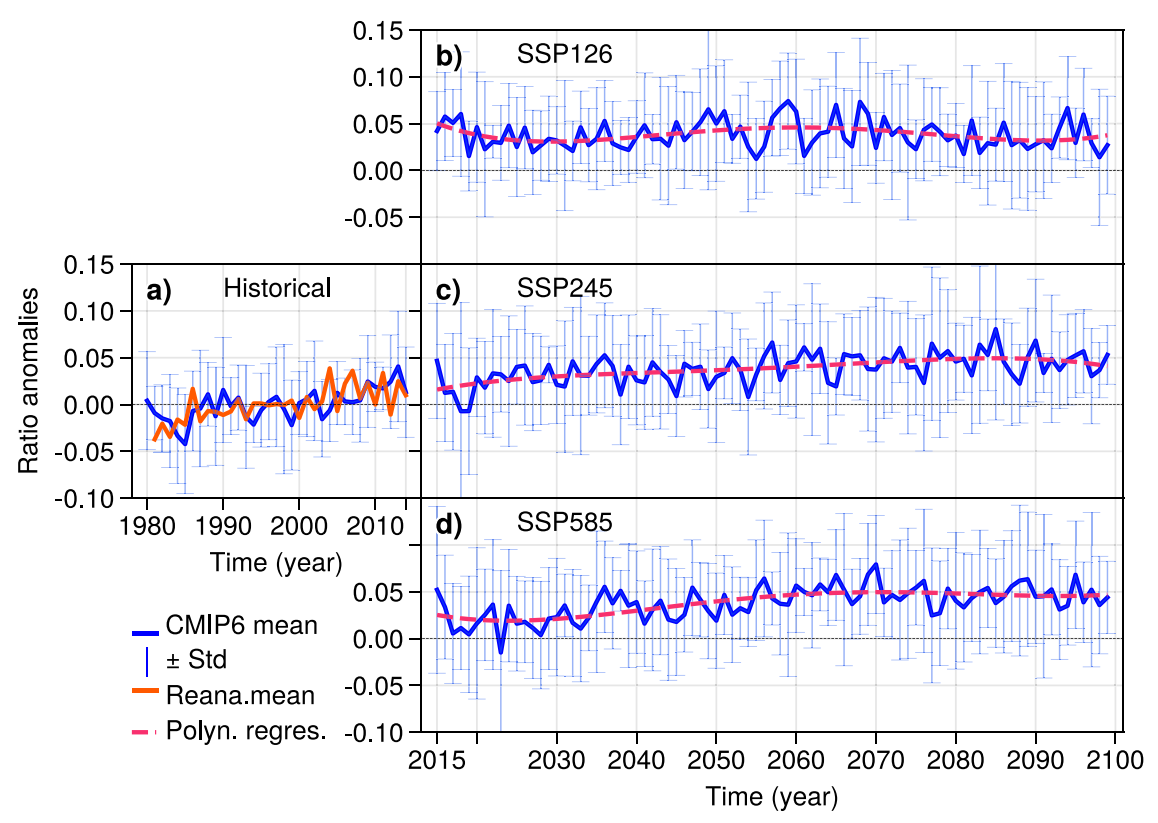

FIG. 13. Time series of average VT/SE ratio anomalies excluding north China where decreasing trends are shown in Fig. 12a. Thick blue lines are the ensemble mean of the 13 CMIP6 models, vertical bars are the ensemble spread, and dashed orange lines are the nonlinear regression. The solid orange line shows the mean of the five reanalysis datasets.

availability in soil (i.e., the area is water limited). Therefore, the decreased VT/SE ratio in north China grasslands (Figs. 10 and 12) over 1981-2014 is a result of concurrent long-term soil drying in the context of decreasing precipitation regulated by the interdecadal Pacific oscillation (Yang et al. 2019); the failure to regenerate the trend by CMIP6 models also results from the wetter bias in soil moisture simulations. In south China savanna and evergreen forestlands, which have wetter soil, the available radiation energy controls the pathway of soil moisture loss (i.e., the area is energy limited). For the tight coupling between soil moisture and radiation changes, in subtropical areas, increasing radiation (increasing temperature) enhances vegetation transpiration and water use, causing soil moisture drying. The increased correlations of the ratio with soil moisture (from 0.48 to $-0.78, p<0.01$, Fig. 16) and radiation (0.16-0.53) anomalies reveal the tighter link throughout vegetation, water, and radiation processes over these regions. For this reason, changes in soil moisture loss pathways feature regionality and seasonality under a changing climate.

\section{b. Limitations and uncertainty}

Based on the five reanalysis-like datasets, the ensemble mean showed decreasing trends in north China grasslands and croplands (Fig. 10). In the north China grasslands, the decreasing trends were aligned with that of remote sensing LAI changes (Piao et al. 2020); however, the 13-CMIP6-
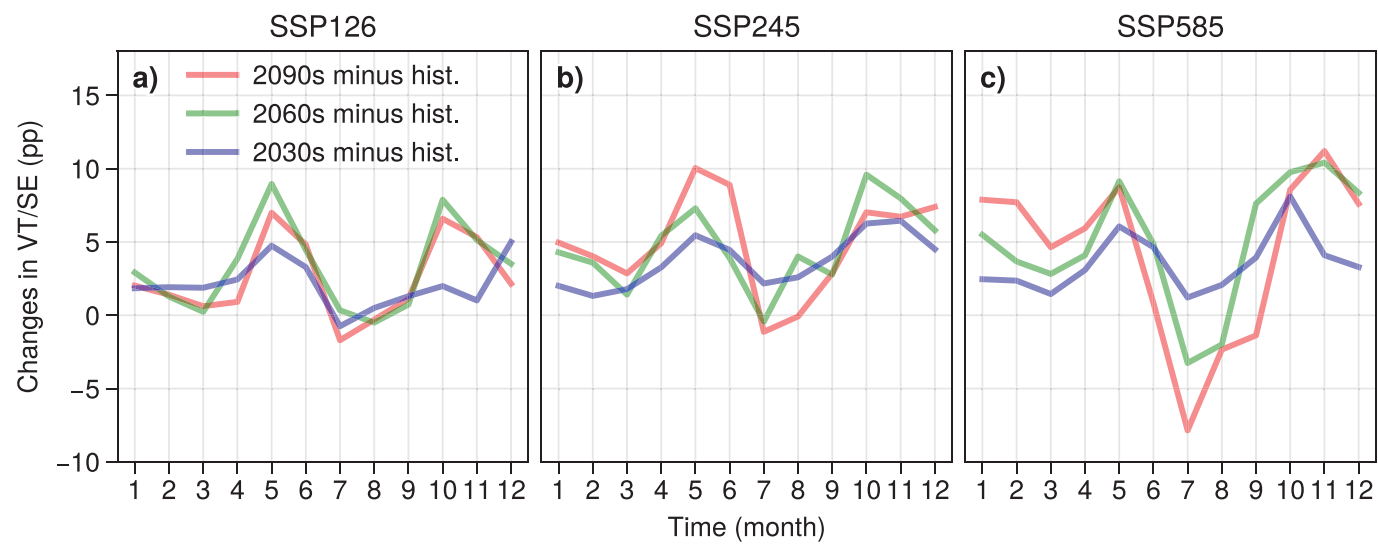

FIG. 14. Projected area-averaged changes in the annual cycle of the VT/SE ratio relative to the period of 1981-2014 for the three climate scenarios (SSP126, 245, and 585). The area with decreasing trends (north China, as shown in Fig. 12a) is excluded. 
2030s minus hist.
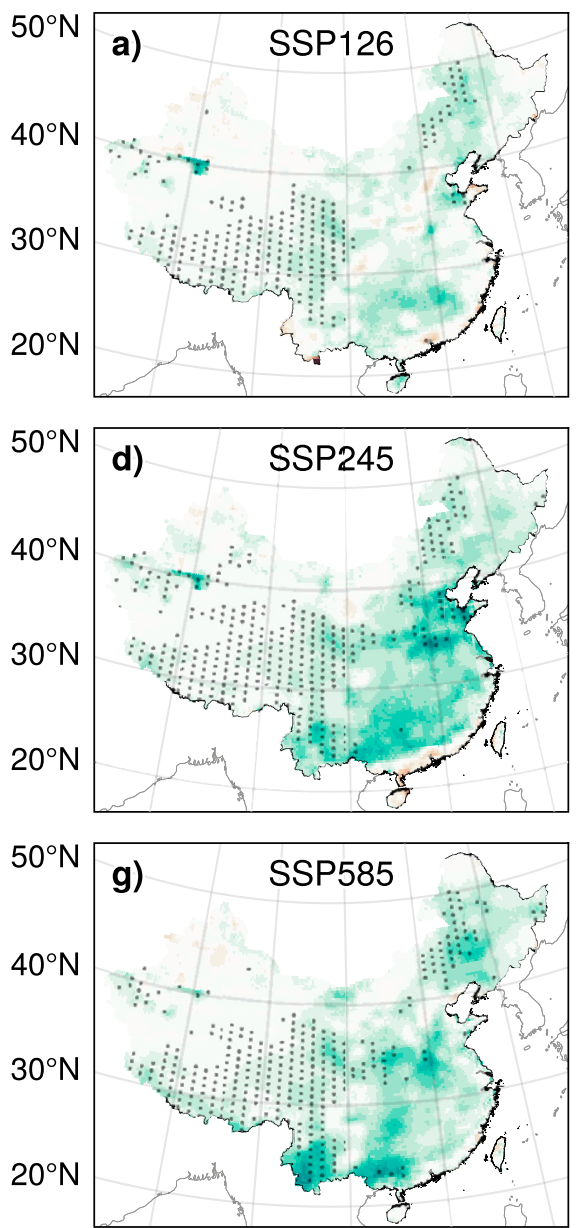

$85^{\circ} \mathrm{E} \quad 95^{\circ} \mathrm{E} \quad 105^{\circ} \mathrm{E} \quad 115^{\circ} \mathrm{E} \quad 125^{\circ} \mathrm{E}$ 2060s minus hist.
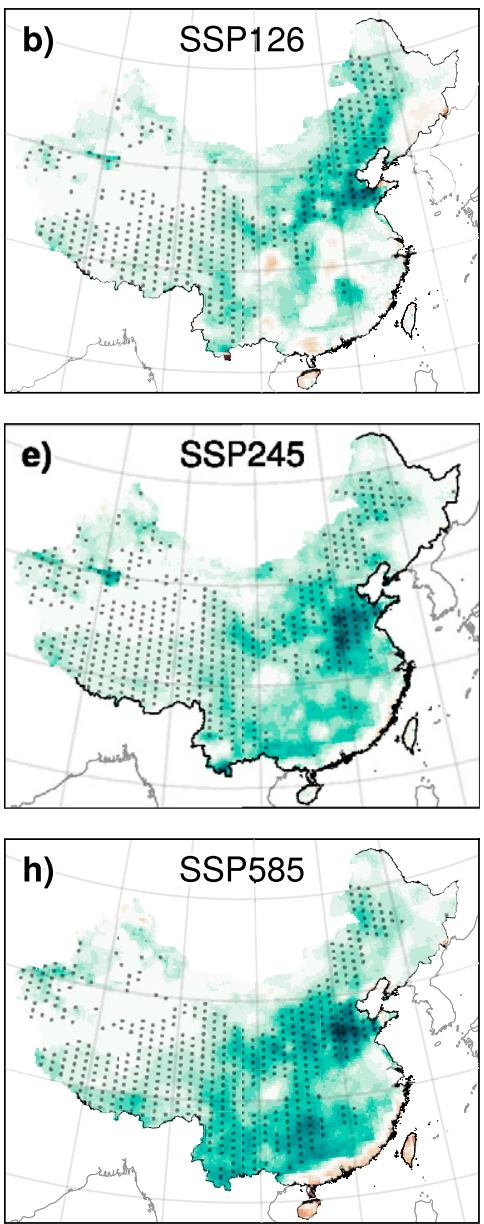

2090s minus hist.
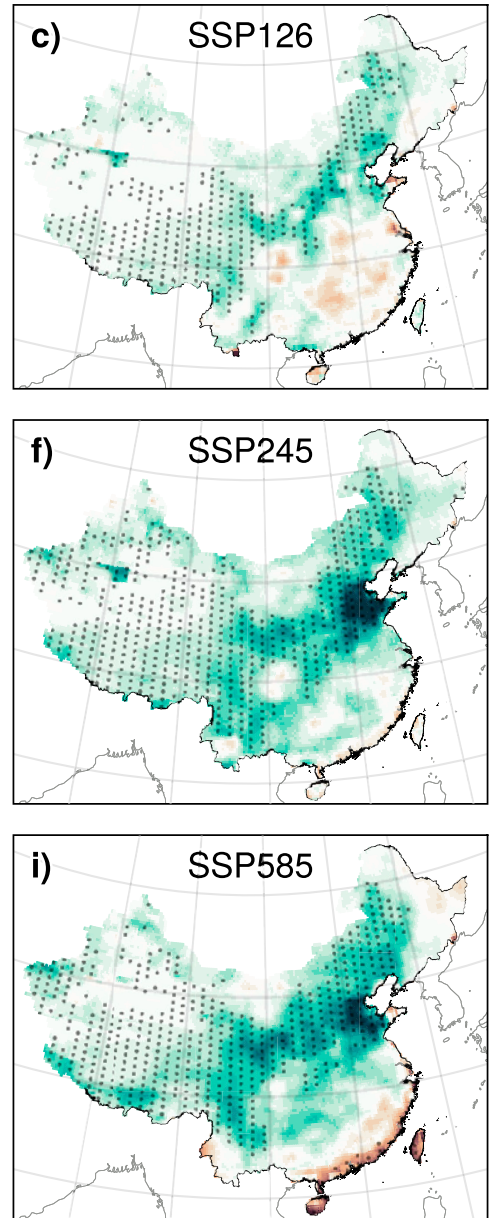

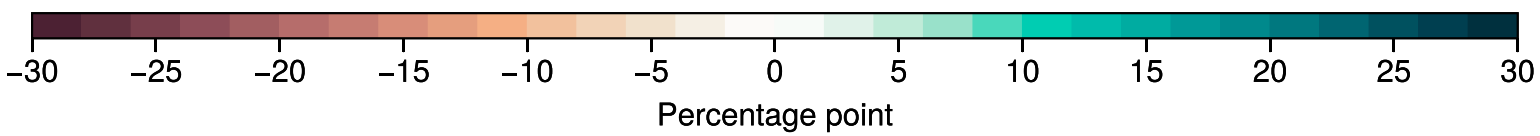

FIG. 15. Projected VT/SE ratio changes relative to the historical period (1981-2014) for the three climate scenarios, where dots indicate statistical significance at the $\alpha=0.05$ level from a paired $t$ test.

model ensemble yielded the opposite trends during the same period. As a result, the increases in the vegetation pathway of soil moisture loss in this region face uncertainties under the three future scenarios. For the croplands, the decreasing trends of the VT/SE ratio were jointly produced by 20CRv3, GLDAS, and ERA5L. In contrast, MERRA2 and GLEAM exhibited increasing trends that were qualitatively consistent with greening trends and the increasing trends from the CMIP6 model mean.

This study summarized the performance of CMIP6 models in terms of soil moisture balance using a metric-based approach; however, it should be noted that Earth system models are complex in nature, and the selection of CMIP6 from the perspective of soil moisture balance is quite challenging and may be inadequate using only two metrics, the VT/SE mean and its long-term trend; thus, different model sets may contribute to differences in the magnitudes of soil moisture loss changes, as noted in (Srivastava et al. 2020). Despite this caveat, the increasing role played by vegetation in the water cycle under a changing climate deserves attention in model development and climate impact studies.

The large spreads of the VT and VT/SE magnitudes among the reanalyses, and relative to the observations and observation-driven estimates (Figs. 4 and 5) were caused mainly by differences in the forcing data. For example, the GLEAM estimates were preferentially forced with satellite observation retrievals. In contrast, the other four reanalyses assimilated 

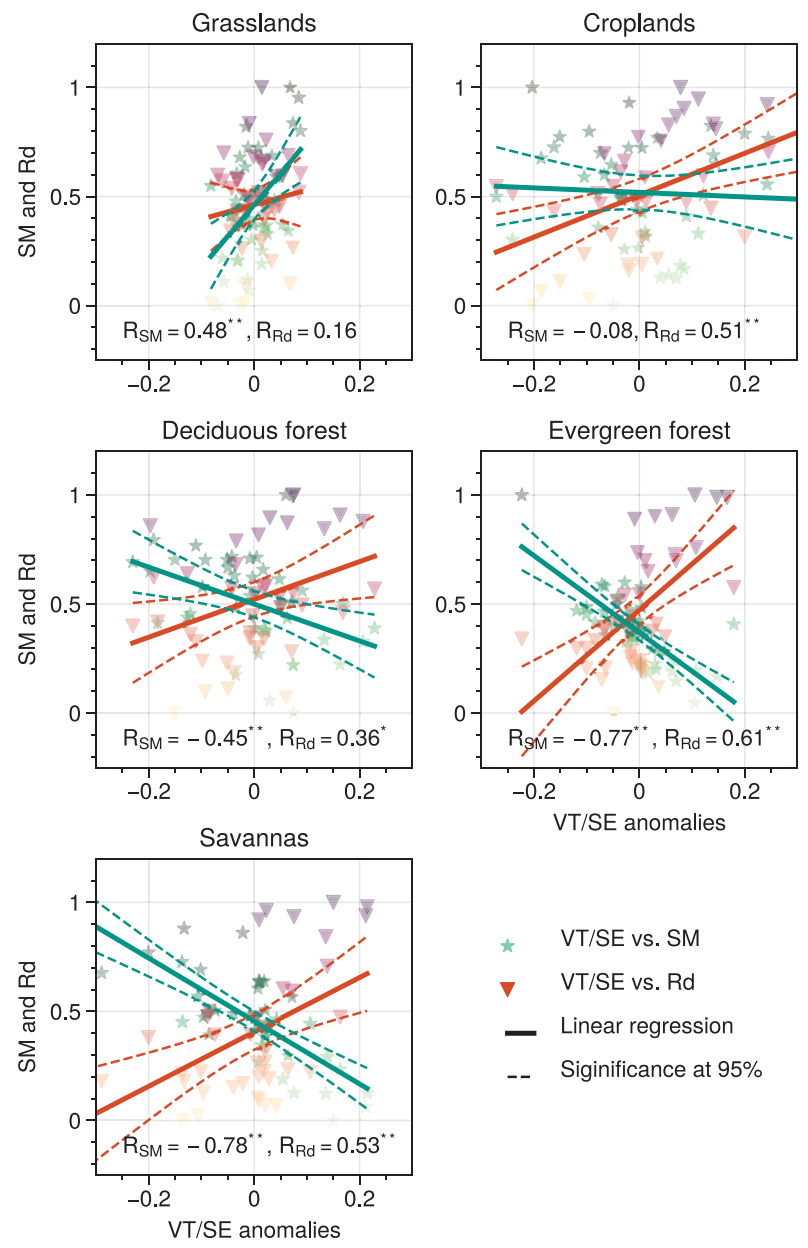

* VT/SE vs. SM

$\nabla \quad V T / S E$ vs. Rd

- Linear regression

-_ Siginificance at $95 \%$

FIG. 16. Joint distributions of the VT/SE ratio with anomalies of soil moisture (SM) and surface downward solar radiation (Rd) for five dominant vegetation types during 1981-2014. The linear relationships (solid lines) between the VT/SE ratio and SM or Rd were derived from ordinary least squares regressions. The $R$ denotes the Pearson correlation coefficient with statistical significance at the $p<0.01(* *)$ or $0.05(*)$ level.

few satellite observations, especially precipitation data. In particular, the larger VT/SE ratios in the GLEAM data, similar to those during 2005-07 [Fig. 11 in Miralles et al. (2016)], resulted from the far lower partitioning of soil evaporation. Separately calculating the components of evapotranspiration, i.e., transpiration and soil evaporation, together with the data assimilation algorithm, may account for the large ratios in GLEAM (Martens et al. 2017). In the case of ERA5L, the negative $\mathrm{VT} / \mathrm{SE}$ trend is attributed to the strong vegetation response to the soil moisture decline in north China (e.g., Fig. 12). In the other reanalysis products, the lower VT/SE ratio is associated with the inadequate representation of water vapor diffusion in the soil within Earth system models (Chang et al. 2018). LAI is another important driver of the modeled VT/SE variability, and thus, inaccuracies in its values may directly lead to lower VT/SE ratios in the models (Lian et al. 2018). In addition, the reanalysis and CMIP6 model systems have yet to adequately represent the processes of the terrestrial water cycle (e.g., groundwater), vegetation processes (succession, extension, plant root dynamics), and human activities (agricultural management, afforestation) (Best et al. 2011; Dai et al. 2003; Dunne et al. 2020; Lawrence et al. 2019), thereby contributing uncertainties to the simulations of the partitioning of evapotranspiration. As a result, the lower VT/ SE ratio in the present study relative to observation-based estimates may underestimate the changes in the soil moisture loss in historical and future climates.

Note that the in situ observations and observation-based benchmark data are influenced to various degrees by human activities, such as land use and land cover changes and irrigation, which have yet to be explicitly considered in Earth system models. Moreover, mismatches in the spatial scale between point-scale in situ observations and model grid means may undermine the effectiveness of model validations using in situ observations (Entekhabi et al. 2010). On the other hand, measuring vegetation transpiration is still a challenging task, and discrepancies among benchmark data are still considerable (Miralles et al. 2016; Zhang et al. 2016).

Accordingly, accurately quantifying the historical and future changes in the VT/SE ratio on regional scales using Earth system models remains a challenging task given the inadequate representations of surface water, energy, and carbon interactions. Nevertheless, the credibility of ensemble means in predicting the overall relative changes or trends in surface processes provides reasonable confidence in the simulated and projected response of VT/SE to the warming climate and thus in the first-order knowledge of the VT/SE response to climate change.

\section{c. Implications of pathway changes for terrestrial environments}

Increases in the VT/SE ratio clarify the process of increasing soil water loss by vegetation transpiration instead of by the soil evaporation pathway. Such a change in water balance can increase water loss in the root soil layer (Shellito et al. 2018), resulting in the variability of the terrestrial water cycle on various temporal scales. In past decades, changes in soil moisture persistence have been observed across China ( $\mathrm{Li}$ et al. 2020b). This observation coupled with the changes in land surface properties such as roughness and albedo and the radiation energy balance trigger feedback changes in land-atmosphere systems, especially over semiarid and subhumid regions that have strong land-atmosphere coupling (Koster et al. 2004). Therefore, future studies can shed light on climate change and terrestrial environments in these regions in terms of the feedbacks between the land and atmosphere.

Increases in the VT/SE ratio are highly associated with the physiological processes of vegetation. The historical trends and projections for the future promise positive trends related to the carbon budget and sequestration as the vegetation function is enhanced across China. To fulfill such a potential, particularly over semiarid and subhumid regions, ecological efforts should be made consistently. 
Additionally, the enhancement of the vegetation pathway of soil moisture loss increases both the risk of soil aridification, especially in deep soil, due to root uptake (Schenk and Jackson 2002) and the decrease in runoff due to vertical water cycle changes and alteration of precipitation patterns through land-atmosphere feedbacks (Zhou et al. 2021).

\section{Summary and conclusions}

Global warming drives changes not only in the atmospheric climate but also in the feedbacks of surface processes, leading to surface water balance variations and environmental changes. This paper aimed to investigate the responses of soil moisture to the changing climate while focusing on the pathway changes in soil moisture loss, namely, the VT/SE ratio. The investigation was based on combining reanalysis datasets and CMIP6 climate model projections. Five reanalysis datasets were first evaluated using in situ observations of soil moisture and vegetation transpiration as well as benchmark data for evapotranspiration. Thirteen CMIP6 projections under three emission scenarios (SSP126, SSP245, and SSP585) were selected after some cross validation of their historical simulations with the reanalysis datasets. The reanalysis datasets were used to analyze historical changes, while CMIP6 projections were used to analyze the future. Because of limited in situ observations, this study is confined to China only. The main findings are as follows:

- For the present-day climate, there has been a significant change in the balance of soil moisture loss across China, except in the northern arid regions. The VT/SE ratio increased by 51.4 pps according to the reanalysis datasets and by 42.7 pps based on the CMIP6 simulations during the period 1981-2014.

- The CMIP6 projections suggest the historical trends will continue into the twenty-first century. From 2015 to 2100, the increasing loss ratio held with increases of 30.6 and 40.8 pps in comparison with that of historical simulations under SSP245 and SSP58, respectively. The increase featured double peaks in May and October in response to the extension of the growing season under a warming climate.

- The reanalyses and CMIP6 models used herein could generally regenerate changes in soil moisture balance and vegetation processes driven by the warming climate in China during the present period. The increase in the loss ratio, VT/SE, was directly caused by the increasing loss through the vegetation transpiration pathway, while a local decrease occurred in north China due to the decreasing soil moisture.

- The changing soil moisture loss balance may alter and be altered by land-atmosphere feedbacks in terms of the water balance and carbon budget, thus giving rise to effects on the local climate and terrestrial environments. However, the predicted enhancement of vegetation water use efficiency will help counterbalance carbon dioxide emissions in the future.

Acknowledgments. This study was jointly sponsored by the National Key R\&D Program of China (2018YFA0606002), the National Natural Science Foundation of China (42075171), the Jiangsu Collaborative Innovation Center for Climate Change, and the U.K.-China Research and Innovation Partnership Fund through the Met Office Climate Science for Service Partnership (CSSP) China as part of the Newton Fund.

\section{REFERENCES}

Balsamo, G., P. Viterbo, A. Beljaars, B. van den Hurk, M. Hirschi, A. K. Betts, and K. Scipal, 2009: A revised hydrology for the ECMWF model: Verification from field site to terrestrial water storage and impact in the integrated forecast system. J. Hydrometeor., 10, 623-643, https://doi.org/10.1175/2008JHM1068.1.

Bao, Y., Z. Y. Song, and F. L. Qiao, 2020: FIO-ESM version 2.0: Model description and evaluation. J. Geophys. Res. Oceans, 125, e2019JC016036, https://doi.org/10.1029/2019JC016036.

Berg, A., and J. Sheffield, 2019a: Historic and projected changes in coupling between soil moisture and evapotranspiration (ET) in CMIP5 models confounded by the role of different ET components. J. Geophys. Res. Atmos., 124, 5791-5806, https://doi.org/10.1029/2018JD029807.

$\longrightarrow$, and - 2019b: Evapotranspiration partitioning in CMIP5 models: Uncertainties and future projections. J. Climate, 32, 2653-2671, https://doi.org/10.1175/JCLI-D-18-0583.1.

Berthet, L., V. Andréassian, C. Perrin, and P. Javelle, 2009: How crucial is it to account for the antecedent moisture conditions in flood forecasting? Comparison of event-based and continuous approaches on 178 catchments. Hydrol. Earth Syst. Sci., 13, 819-831, https://doi.org/10.5194/hess-13-819-2009.

Best, M. J., and Coauthors, 2011: The Joint UK Land Environment Simulator (JULES), model description - Part 1: Energy and water fluxes. Geosci. Model Dev., 4, 677-699, https://doi. org/10.5194/gmd-4-677-2011.

Bonan, G. B., P. J. Lawrence, K. W. Oleson, S. Levis, M. Jung, M. Reichstein, D. M. Lawrence, and S. C. Swenson, 2011: Improving canopy processes in the Community Land Model version 4 (CLM4) using global flux fields empirically inferred from FLUXNET data. J. Geophys. Res. Biogeosci., 116, G02014, https://doi.org/10.1029/2010JG001593.

Boucher, O., and Coauthors, 2020: Presentation and evaluation of the IPSL-CM6A-LR climate model. J. Adv. Model. Earth Syst., 12, e2019MS002010, https://doi.org/10.1029/2019MS002010.

Cao, L. J., Y. N. Zhu, G. L. Tang, F. Yuan, and Z. W. Yan, 2016: Climatic warming in China according to a homogenized data set from 2419 stations. Int. J. Climatol., 36, 4384-4392, https:// doi.org/10.1002/joc.4639.

Chang, L. L., and Coauthors, 2018: Why do large-scale land surface models produce a low ratio of transpiration to evapotranspiration? J. Geophys. Res. Atmos., 123, 9109-9130, https://doi.org/10.1029/2018JD029159.

Chen, C., and Coauthors, 2019: China and India lead in greening of the world through land-use management. Nat. Sustain., 2, 122-129, https://doi.org/10.1038/s41893-019-0220-7.

Cherchi, A., and Coauthors, 2019: Global mean climate and main patterns of variability in the CMCC-CM2 coupled model. $J$. Adv. Model. Earth Syst., 11, 185-209, https://doi.org/10.1029/ 2018MS001369.

Cleveland, R. B., W. S. Cleveland, J. E. McRae, and I. Terpenning, 1990: STL: A seasonal-trend decomposition procedure based on loess. J. Off. Stat., 6, 3-33.

Cleveland, W. S., 1979: Robust locally weighted regression and smoothing scatterplots. J. Amer. Stat. Assoc., 74, 829-836, https://doi.org/10.1080/01621459.1979.10481038. 
Cook, B. I., J. E. Smerdon, R. Seager, and S. Coats, 2014: Global warming and 21st century drying. Climate Dyn., 43, 26072627, https://doi.org/10.1007/s00382-014-2075-y.

Cortés, J., M. D. Mahecha, M. Reichstein, R. B. Myneni, C. Chen, and A. Brenning, 2021: Where are global vegetation greening and browning trends significant? Geophys. Res. Lett., 48, e2020GL091496, https://doi.org/10.1029/2020GL091496.

Dai, Y. J., and Coauthors, 2003: The Common Land Model. Bull. Amer. Meteor. Soc., 84, 1013-1024, https://doi.org/10.1175/ BAMS-84-8-1013.

Danabasoglu, G., and Coauthors, 2020: The Community Earth System Model version 2 (CESM2). J. Adv. Model. Earth Syst., 12, e2019MS001916, https://doi.org/10.1029/2019MS001916.

Decharme, B., and Coauthors, 2019: Recent changes in the ISBACTRIP land surface system for use in the CNRM-CM6 climate model and in global off-line hydrological applications. J. Adv. Model. Earth Syst., 11, 1207-1252, https://doi.org/10. 1029/2018MS001545.

Diffenbaugh, N. S., D. L. Swain, and D. Touma, 2015: Anthropogenic warming has increased drought risk in California. Proc. Natl. Acad. Sci. USA, 112, 3931-3936, https://doi.org/10.1073/ pnas. 1422385112

D'Odorico, P., and A. Porporato, 2004: Preferential states in soil moisture and climate dynamics. Proc. Natl. Acad. Sci. USA, 101, 8848-8851, https://doi.org/10.1073/pnas.0401428101.

Dorigo, W. A., and Coauthors, 2011: The International Soil Moisture Network: A data hosting facility for global in situ soil moisture measurements. Hydrol. Earth Syst. Sci., 15, 16751698, https://doi.org/10.5194/hess-15-1675-2011.

—, and - 2021: The International Soil Moisture Network: Serving Earth system science for over a decade. Hydrol. Earth Syst. Sci., 25, 5749-5804, https://doi.org/10.5194/hess-255749-2021.

Döscher, R., and Coauthors, 2021: The EC-Earth3 Earth system model for the Climate Model Intercomparison Project 6. Geosci. Model Dev. Discuss., 2021, 1-90, https://doi.org/10.5194/ gmd-2020-446.

Dunne, J. P., and Coauthors, 2020: The GFDL Earth System Model Version 4.1 (GFDL-ESM 4.1): Overall coupled model description and simulation characteristics. J. Adv. Model. Earth Syst., 12, e2019MS002015, https://doi.org/10.1029/ 2019MS002015

Dutra, E., J. Munoz-Sabater, S. Boussetta, T. Komori, S. Hirahara, and G. Balsamo, 2020: Environmental lapse rate for high-resolution land surface downscaling: An application to ERA5. Earth Space Sci., 7, e2019EA000984, https://doi.org/ 10.1029/2019EA000984.

Entekhabi, D., R. H. Reichle, R. D. Koster, and W. T. Crow, 2010: Performance metrics for soil moisture retrievals and application requirements. J. Hydrometeor., 11, 832-840, https://doi.org/10.1175/2010JHM1223.1.

Gelaro, R., and Coauthors, 2017: The Modern-Era Retrospective Analysis for Research and Applications, version 2 (MERRA-2). J. Climate, 30, 5419-5454, https://doi.org/10.1175/JCLI-D-160758.1.

Gettelman, A., and Coauthors, 2019: The Whole Atmosphere Community Climate Model version 6 (WACCM6). J. Geophys. Res. Atmos., 124, 12380-12403, https://doi.org/10.1029/ 2019JD030943.

Green, J. K., S. I. Seneviratne, A. M. Berg, K. L. Findell, S. Hagemann, D. M. Lawrence, and P. Gentine, 2019: Large influence of soil moisture on long-term terrestrial carbon uptake. Nature, 565, 476-479, https://doi.org/10.1038/s41586018-0848-x.

IPCC, 2001: Climate Change 2001: The Scientific Basis. Cambridge University Press, $881 \mathrm{pp}$.

Ji, J. J., 1995: A climate-vegetation interaction model: Simulating physical and biological processes at the surface. J. Biogeogr. 22, 445-451, https://doi.org/10.2307/2845941.

Jones, A. R., and N. A. Brunsell, 2009: Energy balance partitioning and net radiation controls on soil moisture-precipitation feedbacks. Earth Interact., 13, https://doi.org/10.1175/2009EI270.1.

Jung, M., and Coauthors, 2010: Recent decline in the global land evapotranspiration trend due to limited moisture supply. Nature, 467, 951-954, https://doi.org/10.1038/nature09396.

- , and Coauthors, 2019: The FLUXCOM ensemble of global land-atmosphere energy fluxes. Sci. Data, 6, 74, https://doi. org/10.1038/s41597-019-0076-8.

Keenan, T. F., D. Y. Hollinger, G. Bohrer, D. Dragoni, J. W. Munger, H. P. Schmid, and A. D. Richardson, 2013: Increase in forest water-use efficiency as atmospheric carbon dioxide concentrations rise. Nature, 499, 324-327, https://doi.org/10. 1038/nature12291.

Kelley, M., and Coauthors, 2020: GISS-E2.1: Configurations and climatology. J. Adv. Model. Earth Syst., 12, e2019MS002025, https://doi.org/10.1029/2019MS002025.

Koster, R. D., and M. J. Suarez, 1996: The influence of land surface moisture retention on precipitation statistics. J. Climate, 9, 2551-2567, https://doi.org/10.1175/1520-0442(1996)009 $<2551$ :TIOLSM $>2.0$.CO;2

— , and Coauthors, 2004: Regions of strong coupling between soil moisture and precipitation. Science, 305, 1138-1140, https:// doi.org/10.1126/science.1100217.

Krinner, G., and Coauthors, 2005: A dynamic global vegetation model for studies of the coupled atmosphere-biosphere system. Global Biogeochem. Cycles, 19, GB1015, https://doi.org/ 10.1029/2003GB002199.

Lawrence, D. M., and Coauthors, 2011: Parameterization improvements and functional and structural advances in version 4 of the Community Land Model. J. Adv. Model. Earth Syst., 3, M03001, https://doi.org/10.1029/2011MS000045.

, and - 2019: The Community Land Model version 5: Description of new features, benchmarking, and impact of forcing uncertainty. J. Adv. Model. Earth Syst., 11, 42454287, https://doi.org/10.1029/2018MS001583.

Lee, J., J. Kim, M.-A. Sun, B.-H. Kim, H. Moon, H. M. Sung, J. Kim, and Y.-H. Byun, 2020: Evaluation of the Korea Meteorological Administration Advanced Community Earth-System model (K-ACE). Asia-Pac. J. Atmos. Sci., 56, 381-395, https:// doi.org/10.1007/s13143-019-00144-7.

Lee, W. L., and Coauthors, 2020: Taiwan Earth System Model version 1: Description and evaluation of mean state. Geosci. Model Dev., 13, 3887-3904, https://doi.org/10.5194/gmd-133887-2020.

Li, L. J., and Coauthors, 2020: The Flexible Global Ocean-Atmosphere-Land System model grid-point version 3 (FGOALSg3): Description and evaluation. J. Adv. Model. Earth Syst., 12, e2019MS002012, https://doi.org/10.1029/2019MS002012.

Li, M. X., and Z. G. Ma, 2015: Soil moisture drought detection and multi-temporal variability across China. Sci. China Earth Sci., 58, 1798-1813, https://doi.org/10.1007/s11430-015-5076-8.

— , P. L. Wu, and Z. G. Ma, 2020a: A comprehensive evaluation of soil moisture and soil temperature from third-generation atmospheric and land reanalysis data sets. Int. J. Climatol., 40, 5744-5766, https://doi.org/10.1002/joc.6549. 
,,--- M. X. Lv, and Q. Yang, 2020b: Changes in soil moisture persistence in China over the past 40 years under a warming climate. J. Climate, 33, 9531-9550, https://doi.org/10. 1175/JCLI-D-19-0900.1.

Lian, X., and Coauthors, 2018: Partitioning global land evapotranspiration using CMIP5 models constrained by observations. Nat. Climate Change, 8, 640-646, https://doi.org/10. 1038/s41558-018-0207-9.

Liu, L., L. Gudmundsson, M. Hauser, D. Qin, S. Li, and S. I. Seneviratne, 2020: Soil moisture dominates dryness stress on ecosystem production globally. Nat. Commun., 11, 4892, https:// doi.org/10.1038/s41467-020-18631-1.

Lucht, W., and Coauthors, 2002: Climatic control of the high-latitude vegetation greening trend and Pinatubo effect. Science, 296, 1687-1689, https://doi.org/10.1126/science.1071828.

Ma, S. M., T. J. Zhou, A. G. Dai, and Z. Y. Han, 2015: Observed changes in the distributions of daily precipitation frequency and amount over China from 1960 to 2013. J. Climate, 28, 6960-6978, https://doi.org/10.1175/JCLI-D-15-0011.1.

Martens, B., and Coauthors, 2017: GLEAM v3: Satellite-based land evaporation and root-zone soil moisture. Geosci. Model Dev., 10, 1903-1925, https://doi.org/10.5194/gmd-10-1903-2017.

Meng, X., and Coauthors, 2021: A fine-resolution soil moisture dataset for China in 2002-2018. Earth Syst. Sci. Data, 13, 3239-3261, https://doi.org/10.5194/essd-2020-292.

Miralles, D. G., and Coauthors, 2016: The WACMOS-ET project - Part 2: Evaluation of global terrestrial evaporation data sets. Hydrol. Earth Syst. Sci., 20, 823-842, https://doi. org/10.5194/hess-20-823-2016.

Mu, Q. Z., M. S. Zhao, and S. W. Running, 2011: Improvements to a MODIS global terrestrial evapotranspiration algorithm. Remote Sens. Environ., 115, 1781-1800, https://doi.org/10. 1016/j.rse.2011.02.019.

Mueller, B., and Coauthors, 2013: Benchmark products for land evapotranspiration: LandFlux-EVAL multi-data set synthesis. Hydrol. Earth Syst. Sci., 17, 3707-3720, https://oi.org/10. 5194/hess-17-3707-2013.

Müller, W. A., and Coauthors, 2018: A higher-resolution version of the Max Planck Institute Earth System Model (MPIESM1.2-HR). J. Adv. Model. Earth Syst., 10, 1383-1413, https://doi.org/10.1029/2017MS001217.

Muñoz-Sabater, J., and Coauthors, 2021: ERA5-land: A state-ofthe-art global reanalysis dataset for land applications. Earth Syst. Sci. Data, 13, 4349-4383, https://doi.org/10.5194/essd-134349-2021.

Nelson, J. A., and Coauthors, 2020: Ecosystem transpiration and evaporation: Insights from three water flux partitioning methods across FLUXNET sites. Global Change Biol., 26, 69166930, https://doi.org/10.1111/gcb.15314.

Niu, Z., and Coauthors, 2019: An increasing trend in the ratio of transpiration to total terrestrial evapotranspiration in China from 1982 to 2015 caused by greening and warming. Agric. For. Meteor., 279, 107701, https://doi.org/10.1016/j.agrformet. 2019.107701.

— H. He, G. Zhu, X. Ren, L. Zhang, and K. Zhang, 2020: A spatial-temporal continuous dataset of the transpiration to evapotranspiration ratio in China from 1981-2015. Sci. Data, 7, 369, https://doi.org/10.1038/s41597-020-00693-x.

Nobuhiro, T., and Coauthors, 2007: Year-round observation of evapotranspiration in an evergreen broadleaf forest in Cambodia. Forest Environments in the Mekong River Basin, $\mathrm{H}$. Sawada et al., Eds., Springer, 75-86, https://doi.org/10.1007/ 978-4-431-46503-4_7.
O’Grady, A. P., D. Eamus, and L. B. Hutley, 1999: Transpiration increases during the dry season: Patterns of tree water use in eucalypt open-forests of northern Australia. Tree Physiol., 19, 591-597, https://doi.org/10.1093/treephys/19.9.591.

Perez-Priego, O., G. Katul, M. Reichstein, T. S. El-Madany, B. Ahrens, A. Carrara, T. M. Scanlon, and M. Migliavacca, 2018: Partitioning eddy covariance water flux components using physiological and micrometeorological approaches. $J$. Geophys. Res. Biogeosci., 123, 3353-3370, https://doi.org/10. 1029/2018JG004637.

Philip, J. R., 1966: Plant water relations - Some physical aspects. Annu. Rev. Plant Physiol., 17, 245-268, https://doi.org/10. 1146/annurev.pp.17.060166.001333.

Piao, S., and Coauthors, 2020: Characteristics, drivers and feedbacks of global greening. Nat. Rev. Earth Environ., 1, 14-27, https://doi.org/10.1038/s43017-019-0001-x.

Robinson, D. A., and Coauthors, 2008: Soil moisture measurement for ecological and hydrological watershed-scale observatories: A review. Vadose Zone J., 7, 358-389, https://doi. org/10.2136/vzj2007.0143.

Rodell, M., and Coauthors, 2004: The Global Land Data Assimilation System. Bull. Amer. Meteor. Soc., 85, 381-394, https:// doi.org/10.1175/BAMS-85-3-381.

Rong, X., J. Li, H. Chen, J. Su, L. Hua, Z. Zhang, and Y. Xin, 2020: The CMIP6 historical simulation datasets produced by the climate system model CAMS-CSM. Adv. Atmos. Sci., 38, 285-295, https://doi.org/10.1007/s00376-020-0171-y.

Schenk, H. J., and R. B. Jackson, 2002: Rooting depths, lateral root spreads and below-ground/above-ground allometries of plants in water-limited ecosystems. J. Ecol., 90, 480-494, https://doi.org/10.1046/j.1365-2745.2002.00682.x.

Schmidt, G. A., and Coauthors, 2006: Present-day atmospheric simulations using GISS ModelE: Comparison to in situ, satellite, and reanalysis data. J. Climate, 19, 153-192, https://doi. org/10.1175/JCLI3612.1.

Séférian, R., and Coauthors, 2019: Evaluation of CNRM Earth system model, CNRM-ESM2-1: Role of Earth system processes in present-day and future climate. J. Adv. Model. Earth Syst., 11, 4182-4227, https://doi.org/10.1029/2019MS001791.

Seland, O., and Coauthors, 2020: Overview of the Norwegian Earth System Model (NorESM2) and key climate response of CMIP6 DECK, historical, and scenario simulations. Geosci. Model Dev., 13, 6165-6200, https://doi.org/10.5194/gmd13-6165-2020.

Sellar, A. A., and Coauthors, 2019: UKESM1: Description and evaluation of the UK Earth System Model. J. Adv. Model. Earth Syst., 11, 4513-4558, https://doi.org/10.1029/2019MS001739.

Seneviratne, S. I., T. Corti, E. L. Davin, M. Hirschi, E. B. Jaeger, I. Lehner, B. Orlowsky, and A. J. Teuling, 2010: Investigating soil moisture-climate interactions in a changing climate: A review. Earth-Sci. Rev., 99, 125-161, https://doi.org/10.1016/j. earscirev.2010.02.004.

Sheffield, J., G. Goteti, and E. F. Wood, 2006: Development of a 50-yr high-resolution global dataset of meteorological forcings for land surface modeling. J. Climate, 19, 3088-3111, https://doi.org/10.1175/JCLI3790.1.

Shellito, P. J., E. E. Small, and B. Livneh, 2018: Controls on surface soil drying rates observed by SMAP and simulated by the Noah land surface model. Hydrol. Earth Syst. Sci., 22, 1649-1663, https://doi.org/10.5194/hess-22-1649-2018.

Siniksaran, E., 2005: On the geometry of F, Wald, LR, and LM tests in linear regression models. Statistics, 39, 287-299, https://doi.org/10.1080/02331880500178521. 
Slivinski, L. C., and Coauthors, 2019: Towards a more reliable historical reanalysis: Improvements for version 3 of the twentieth century reanalysis system. Quart. J. Roy. Meteor. Soc., 145, 2876-2908, https://doi.org/10.1002/qj.3598.

Smith, B., D. Warlind, A. Arneth, T. Hickler, P. Leadley, J. Siltberg, and S. Zaehle, 2014: Implications of incorporating $\mathrm{N}$ cycling and $\mathrm{N}$ limitations on primary production in an individual-based dynamic vegetation model. Biogeosciences, 11, 2027-2054, https://doi.org/10.5194/bg-11-2027-2014.

Song, Q. H., and Coauthors, 2017: Water use efficiency in a primary subtropical evergreen forest in southwest China. Sci. Rep., 7, 43031, https://doi.org/10.1038/srep43031.

Srivastava, A., R. Grotjahn, and P. A. Ullrich, 2020: Evaluation of historical CMIP6 model simulations of extreme precipitation over contiguous US regions. Wea. Climate Extreme, 29, 100268, https://doi.org/10.1016/j.wace.2020.100268.

Stevens, B., and Coauthors, 2013: Atmospheric component of the MPI-M Earth System Model: ECHAM6. J. Adv. Model. Earth Syst., 5, 146-172, https://doi.org/10.1002/jame.20015.

Swart, N. C., and Coauthors, 2019: The Canadian Earth System Model version 5 (CanESM5.0.3). Geosci. Model Dev., 12, 4823-4873, https://doi.org/10.5194/gmd-12-4823-2019.

Takata, K., S. Emori, and T. Watanabe, 2003: Development of the minimal advanced treatments of surface interaction and runoff. Global Planet. Change, 38, 209-222, https://doi.org/10. 1016/S0921-8181(03)00030-4.

Tanaka, K., and Coauthors, 2003: Transpiration peak over a hill evergreen forest in northern Thailand in the late dry season: Assessing the seasonal changes in evapotranspiration using a multilayer model. J. Geophys. Res., 108, 4533, https://doi.org/ 10.1029/2002JD003028.

Tatebe, H., and Coauthors, 2019: Description and basic evaluation of simulated mean state, internal variability, and climate sensitivity in MIROC6. Geosci. Model Dev., 12, 2727-2765, https://doi.org/10.5194/gmd-12-2727-2019.

Taylor, C. M., R. A. de Jeu, F. Guichard, P. P. Harris, and W. A. Dorigo, 2012: Afternoon rain more likely over drier soils. Nature, 489, 423-426, https://doi.org/10.1038/nature11377.

Verseghy, D. L., N. A. Mcfarlane, and M. Lazare, 1993: CLASS A Canadian land-surface scheme for GCMS.2. vegetation model and coupled runs. Int. J. Climatol., 13, 347-370, https:// doi.org/10.1002/joc.3370130402.

Voldoire, A., and Coauthors, 2013: The CNRM-CM5.1 global climate model: Description and basic evaluation. Climate Dyn., 40, 2091-2121, https://doi.org/10.1007/s00382-011-1259-y.

— , and Coauthors, 2019: Evaluation of CMIP6 DECK experiments with CNRM-CM6-1. J. Adv. Model. Earth Syst., 11, 2177-2213, https://doi.org/10.1029/2019MS001683.

Wang, K. C., P. C. Wang, J. M. Liu, M. Sparrow, S. Haginoya, and X. J. Zhou, 2005: Variation of surface albedo and soil thermal parameters with soil moisture content at a semi-desert site on the western Tibetan Plateau. Bound.-Layer Meteor., 116, 117-129, https://doi.org/10.1007/s10546-004-7403-z.

Williams, D. G., and Coauthors, 2004: Evapotranspiration components determined by stable isotope, sap flow and eddy covariance techniques. Agric. For. Meteor., 125, 241-258, https://doi. org/10.1016/j.agrformet.2004.04.008.

Williams, K. D., and Coauthors, 2018: The Met Office Global Coupled Model 3.0 and 3.1 (GC3.0 and GC3.1) configurations. J. Adv. Model. Earth Syst., 10, 357-380, https://doi.org/ 10.1002/2017MS001115.

Winter, D. A., H. G. Sidwall, and D. A. Hobson, 1974: Measurement and reduction of noise in kinematics of locomotion. $J$.
Biomech., 7, 157-159, https://doi.org/10.1016/0021-9290(74) 90056-6.

Wu, G., Y. Liu, B. He, Q. Bao, A. Duan, and F. F. Jin, 2012: Thermal controls on the Asian summer monsoon. Sci. Rep., 2, 404, https://doi.org/10.1038/srep00404.

Wu, T. W., and Coauthors, 2019: The Beijing Climate Center Climate System Model (BCC-CSM): The main progress from CMIP5 to CMIP6. Geosci. Model Dev., 12, 1573-1600, https://doi.org/10.5194/gmd-12-1573-2019.

Xie, Z. H., and Coauthors, 2018: A high-resolution land model with groundwater lateral flow, water use, and soil freeze-thaw front dynamics and its application in an endorheic basin. $J$. Geophys. Res. Atmos., 123, 7204-7222, https://doi.org/10.1029/ 2018JD028369.

Yang, Q., Z. G. Ma, P. L. Wu, N. P. Klingaman, and L. X. Zhang, 2019: Interdecadal seesaw of precipitation variability between North China and the southwest United States. J. Climate, 32, 2951-2968, https://doi.org/10.1175/JCLI-D-18-0082.1.

Yu, G. R., X. F. Wen, X. M. Sun, B. D. Tanner, X. H. Lee, and J. Y. Chen, 2006: Overview of ChinaFLUX and evaluation of its eddy covariance measurement. Agric. For. Meteor., 137, 125-137, https://doi.org/10.1016/j.agrformet.2006.02.011.

Yukimoto, S., and Coauthors, 2012: A new global climate model of the meteorological research institute: MRI-CGCM3-model description and basic performance. J. Meteor. Soc. Japan, 90A, 23-64, https://doi.org/10.2151/jmsj.2012-A02.

$\longrightarrow$, and — 2019: The meteorological research institute Earth system model version 2.0, MRI-ESM2.0: Description and basic evaluation of the physical component. J. Meteor. Soc. Japan, 97, 931-965, https://doi.org/10.2151/jmsj.2019-051.

Zhang, D., X. M. Liu, L. Zhang, Q. Zhang, R. Gan, and X. H. Li, 2020: Attribution of evapotranspiration changes in humid regions of China from 1982 to 2016. J. Geophys. Res. Atmos., 125, e2020JD032404, https://doi.org/10.1029/2020JD032404.

Zhang, H., and Coauthors, 2020: Description and climate simulation performance of CAS-ESM version 2. J. Adv. Model. Earth Syst., 12, e2020MS002210, https://doi.org/10.1029/2020MS002210.

Zhang, Y., and Coauthors, 2012: Decadal trends in evaporation from global energy and water balances. J. Hydrometeor., 13, 379-391, https://doi.org/10.1175/JHM-D-11-012.1.

- , and —, 2016: Multi-decadal trends in global terrestrial evapotranspiration and its components. Sci. Rep., 6, 19124, https://doi.org/10.1038/srep19124.

— , and —, 2018: A Climate Data Record (CDR) for the global terrestrial water budget: 1984-2010. Hydrol. Earth Syst. Sci., 22, 241-263, https://doi.org/10.5194/hess-22-241-2018.

- , F. H. S. Chiew, J. Pena-Arancibia, F. B. Sun, H. X. Li, and R. Leuning, 2017: Global variation of transpiration and soil evaporation and the role of their major climate drivers. J. Geophys. Res. Atmos., 122, 6868-6881, https://doi. org/10.1002/2017JD027025.

Zhou, S., B. F. Yu, Y. Zhang, Y. F. Huang, and G. Q. Wang, 2016: Partitioning evapotranspiration based on the concept of underlying water use efficiency. Water Resour. Res., 52, 11601175, https://doi.org/10.1002/2015WR017766.

$\longrightarrow$, and — 2021: Soil moisture-atmosphere feedbacks mitigate declining water availability in drylands. Nat. Climate Change, 11, 38-44, https://doi.org/10.1038/s41558-020-00945-z.

Zhu, Z. C., and Coauthors, 2016: Greening of the Earth and its drivers. Nat. Climate Change, 6, 791-795, https://doi.org/10. 1038/nclimate3004. 